\title{
Paula CANelo*
}

\author{
LA IMPORTANCIA DEL NIVEL MUNICIPAL PARA LA ÚLTIMA DICTADURA \\ MILITAR ARGENTINA. UN ESTUDIO A TRAVÉS DE SUS DOCUMENTOS \\ RESERVADOS Y SECRETOS (1976-1983)
}

\begin{abstract}
RESUMEN
El artículo analiza la importancia que alcanzó el nivel municipal dentro del Plan Político de la última dictadura militar argentina, mediante el estudio de documentos secretos, reservados y públicos, producidos por las más altas esferas del poder militar. El trabajo muestra que el municipio fue un eslabón fundamental del Plan Político del régimen: como instrumento político del control territorial y poblacional "capilar" característico de la dictadura; como espacio autorizado para la participación de una "ciudadanía municipal", a-política y de alcance local; como laboratorio de la apertura política, y como ámbito de gestación de la "dirigencia natural" argentina. Finalmente, identifica elementos comunes y diferencias entre la experiencia de municipalización de la dictadura chilena y el caso argentino.
\end{abstract}

Palabras claves: Argentina, siglo xx, dictadura militar, municipios, planes políticos, participación civil.

\begin{abstract}
This article analyzes the significance municipalities reached within the Political Plan of Argentina's last military dictatorship. Through the study of secrete, classified and public documents that were produced by the highest spheres of military power this paper shows that municipalities served as a fundamental link to the regime's Political Plan in different ways: as a political instrument of territorial and social "capillary" control characteristic of the dictatorship; as an authorized space for the participation of a local reaching, apolitical "municipal citizenship;" as a laboratory of political openness and as a sphere which nurtured "natural leadership" in Argentina. Finally, this paper identifies common and differing elements of the municipalization of the Chilean dictatorship with the Argentinean case.
\end{abstract}

Key words: Argentina, twentieth century, military dictatorship, municipalities, political plans, civil participation.

Recibido: Noviembre 2014.

Aceptado: Marzo 2015.

* Doctora en Ciencias Sociales por la Facultad Latinoamericana de Ciencias Sociales (FLACSO); Investigadora del Consejo Nacional de Investigaciones Científicas y Técnicas (CONICET); Coordinadora del Programa de Investigaciones sobre las Dictaduras del Cono Sur y sus Legados, del Instituto de Altos Estudios Sociales de la UNSAM. Docente concursada de la Universidad de Buenos Aires y de la Universidad Nacional de San Martín. Correo electrónico: pvcanelo@yahoo.com. 


\section{INTRODUCCIÓN $^{1}$}

Durante los últimos años, las Ciencias Sociales asisten a una decidida revitalización del interés por las dictaduras latinoamericanas de la década de 1970. Ello obedece, en gran parte, a que en varios países de la región el crecimiento de las demandas sociales de investigación y de esclarecimiento de la verdad sobre los procesos represivos de estos gobiernos autoritarios, la apertura o reapertura de algunos procesos de enjuiciamiento y la desclasificación de diferentes archivos dictatoriales, entre otras cuestiones, impulsaron una importante rearticulación de las agendas políticas y de investigación social. Las problemáticas más clásicas, como la influencia de la Doctrina de la Seguridad Nacional en la orientación de las dictaduras, o los efectos sociales de las políticas económicas o represivas implementadas, han cedido espacio a nuevas temáticas. Entre ellas ha cobrado nuevo impulso el interés por las estrategias de legitimación de estos paradigmáticos regímenes, sus políticas de generación de consenso y la recepción de las mismas en la sociedad civil ${ }^{2}$.

En Argentina, la reflexión sobre estos procesos durante el autodenominado Proceso de Reorganización Nacional (1976-1983) se ha articulado en torno a dos tipos de análisis: sobre las "actitudes y comportamientos sociales" de la "gente común" y sobre la denominada "participación civil" en las dictaduras, entendida en términos muy amplios ${ }^{3}$.

${ }^{1}$ Deseo agradecer los comentarios que realizaron a una versión anterior de este trabajo los árbitros espe-
cialistas.
${ }^{2}$ Trabajos anteriores en este plano fueron, para el caso argentino, Guillermo O’Donnell, "Democracia en
la Argentina. Micro y macro", en Guillermo O’Donnell, Contrapuntos. Ensayos escogidos sobre autoritaris-
mo y democratización, Buenos Aires, Paidós, 1997, pp. 133-146. Para el caso chileno, José Joaquín Brunner,
Cultura y crisis de hegemonía, Santiago, FLACSO, documento de trabajo N ${ }^{\circ} 197,1983$, entre otros.

${ }^{3}$ Sobre la dictadura argentina, véase: Gabriela Águila y Luciano Alonso (coords.), Procesos represivos y actitudes sociales, Buenos Aires, Prometeo, 2013; Gabriela Águila, "Dictadura y sociedad en Rosario entre 1976 y 1983: actitudes y comportamientos sociales en una perspectiva de análisis regional”, en Ernesto Bohoslavsky, Marina Franco, Mariana Iglesias, Daniel Lvovich (comps.), Problemas de historia reciente del Cono Sur, Buenos Aires, UNGS-Prometeo, 2010, vol. 2, pp. 235-259; Daniel Lvovich, "Sistema político y actitudes sociales en la legitimación de la dictadura militar argentina (1976-1983)", en Ayer, No 75, Madrid, 2009, pp. 275-299; Daniel Lvovich, "Burócratas, amigos, ideólogos y vecinalistas: el reclutamiento de funcionarios municipales de Morón durante la dictadura militar (1976-1983)", en Ernesto Bohoslavsky y Germán Soprano (eds.), Un Estado con rostro humano. Funcionarios e instituciones estatales en Argentina (desde 1880 a la actualidad), Buenos Aires, UNGS-Prometeo, 2010, pp. 411-430; Hugo Quiroga, El tiempo del 'Proceso'. Conflictos y coincidencias entre políticos y militares. 1976-1983, Rosario, Homo Sapiens, 2004; Laura Rodríguez, "Descentralización municipal, intendentes y 'fuerzas vivas' durante el Proceso (1976-1983)", en Cuestiones de Sociología, No 5-6, La Plata, 2009, pp. 369-387; Laura Rodríguez, "Gobierno municipal, descentralización educativa y funcionarios en la provincia de Buenos Aires durante la última dictadura", en Ernesto Bohoslavsky y Germán Soprano (eds.), Un Estado con rostro humano. Funcionarios e instituciones estatales en Argentina (desde 1880 a la actualidad), Buenos Aires, UNGS-Prometeo, 2010, pp. 431-462; Hugo Vezzetti, Guerra, dictadura y sociedad en la Argentina, Buenos Aires, Siglo XXI, 2002. Para el caso uruguayo: Aldo Marchesi, "Una parte del pueblo feliz, contento, alegre'. Los caminos culturales del consenso autoritario durante la dictadura", en Carlos Demasi et al., La dictadura civico-militar. Uruguay, 1973-1985, Montevideo, Ediciones de la Banda Oriental, 2009; Jaime Yaffé, "La dictadura uruguaya (1973-1985): nuevas perspectivas de investigación e interpretación historiográfica”, en Estudios Ibero-Americanos, vol. 38, No 1, Porto Alegre, junio 2012, pp. 13-26. Para el caso chileno: Verónica Valdivia Ortiz de Zárate, Rolando Álvarez Vallejos y Karen Donoso Fritz, La alcaldización de la política. Los municipios en la dictadura pinochetista. Santiago, LOM Ediciones, 2012; Verónica Valdivia Ortiz de Zárate, “¡Estamos en guerra, señores! El régimen 
El estudio de la participación civil ha tenido su mayor desarrollo en torno al llamado "nivel municipal" en detrimento de otros ámbitos, como el provincial o nacional, por diferentes razones. Por un lado, debido a razones metodológicas y de accesibilidad, ya que su escala reducida lo vuelve más abordable para los estudios empíricos. Por otro, porque es en el nivel municipal donde los analistas observan con mayor nitidez la "complicidad" civil con el gobierno de la dictadura, analizando el papel representado por cuadros gubernamentales civiles designados en las intendencias, por ejemplo. Y más aún, porque investigaciones recientes sobre dictaduras contemporáneas a la argentina, como la chilena, muestran que el municipio fue el "centro materializador" de la refundación social que se propuso el régimen del general Augusto Pinochet, y que en Chile se desplegó un vasto y exitoso proceso de "alcaldización de la política" con importantes consecuencias en la configuración de los escenarios políticos actuales ${ }^{4}$.

En este marco, los analistas comparten cierto consenso sobre la importancia alcanzada por el nivel municipal como locus de ejercicio de la política durante la última dictadura argentina. En un contexto de virtual anulación de "la política" en los escenarios nacionales, habría sido en esta suerte de "trastienda del Estado" donde se habría revelado con mayor claridad el juego micropolítico de intereses particulares entre la sociedad (y sus diversas agrupaciones y asociaciones) y el gobierno militar ${ }^{5}$.

Estos avances presentan aun zonas de sombra. Los estudios se han centrado sobre todo en casos particulares (determinados municipios, partidos, departamentos o localidades), lo que aún no ha permitido establecer si se trató de experiencias coyunturales y acotadas, o si el gobierno militar desplegó hacia el nivel municipal una estrategia de más largo alcance, como parte de un plan más general. Además, los analistas se orientaron más al estudio del que podríamos llamar "par civil" de estas experiencias, que al "par militar": así, el interés por las estrategias desplegadas desde el poder militar ha quedado relativamente obturado frente al que despertó la acción de distinto tipo de pequeñas organizaciones, como las asociaciones vecinales o de fomento, los clubes de barrio o clubes culturales, las juntas vecinales y otras organizaciones locales. No existen aún estudios que hayan abordado la importancia del nivel municipal desde la perspectiva del poder militar, como tampoco análisis que vinculen estos fenómenos con el programa político más amplio de la dictadura argentina.

El presente artículo analiza la importancia que alcanzó el nivel municipal en el Plan Político de la última dictadura militar argentina, mediante el estudio de documentos secretos, reservados o de circulación restringida, en su mayoría inéditos, y documentos públicos, producidos por las más altas esferas del poder militar.

El corpus analizado está formado por documentos secretos hallados entre las llamadas Actas de la dictadura, un importante fondo documental descubierto a fines del año 2013 en el edificio Cóndor de la Fuerza Aérea Argentina, que fue sistematizado por la

militar de Pinochet y el 'pueblo', 1973-1980”, en Historia, № 43, vol. I, Santiago, enero-junio 2010, pp. 163201, entre otros.

${ }^{4}$ Valdivia Ortiz de Zárate, Álvarez y Donoso, op. cit., pp. 6-7.

${ }^{5}$ Inés González Bombal, Los vecinazos. Las protestas barriales en el Gran Buenos Aires, 1982-1983, Buenos Aires, Ediciones del IDES, 1988; Oscar Oszlak, "Privatización autoritaria y recreación de la escena política”, en Oscar Ozslak (comp.), Proceso, crisis y transición democrática, Buenos Aires, CEAL, 1984. 
Dirección Nacional de Derechos Humanos y Derecho Internacional Humanitario del Ministerio de Defensa argentino. Este novedoso fondo comprende todas las actas de las reuniones periódicas celebradas entre julio de 1976 y noviembre de 1983 por la Junta Militar (JM), máximo órgano soberano de la dictadura argentina, integrado por los tres comandantes en jefe de las Fuerzas Armadas (Ejército, Armada y Fuerza Aérea). Las Actas de la dictadura incluyen documentos redactados por la misma JM o, bien, elaborados por otras dependencias de gobierno y tratados en las reuniones de la Junta, que en muchos casos fueron hallados por haber sido incluidos completos como anexos de las Actas $^{6}$.

Este trabajo también analiza documentos reservados o de circulación restringida, en su mayoría inéditos, redactados durante el periodo por importantes instituciones de gobierno como la Secretaría General de la Presidencia de la Nación y el Ministerio de Planeamiento, o por organismos militares como la Secretaría General del Estado Mayor General del Ejército, el Ejército Argentino, la Armada Argentina y la Fuerza Aérea Argentina. Otros textos fueron elaborados a título personal por altos funcionarios gubernamentales como: gobernadores o embajadores, o por civiles aliados que operaron como intelectuales o ideólogos del régimen ${ }^{7}$. El corpus se completa con documentos oficiales redactados por la JM, que fueron publicados entre 1976 y 1983, y con prensa del periodo.

A partir de esta novedosa base empírica, el artículo muestra que el municipio fue un eslabón fundamental del Plan Político del régimen militar argentino: como instrumento político del control territorial y poblacional "capilar" característico de la dictadura; como espacio autorizado para la participación de una "ciudadanía municipal" apolítica y de alcance local como laboratorio de la apertura política y como ámbito de gestación de la "dirigencia natural" argentina. Finalmente, identifica elementos comunes y diferencias entre la experiencia de "municipalización política" de la dictadura chilena y el caso argentino.

\section{Los primeros pasos hacia el Plan Político del proceso}

La última dictadura militar argentina diseñó un complejo esquema de funcionamiento del poder que la distinguió de otras experiencias latinoamericanas. Este esquema estaba basado en dos reglas fundamentales: el reparto tripartito del poder entre las Fuerzas Armadas y la supremacía de la JM por sobre el Presidente de la Nación ${ }^{8}$. A partir del golpe de Estado del 24 de marzo de 1976 se estableció un complejo vínculo entre la JM y el Poder Ejecutivo y sus diferentes ámbitos: nacional, provincial y municipal. De acuerdo con el Estatuto para el proceso de reorganización nacional, uno de los Documentos

\footnotetext{
${ }^{6}$ Las Actas de la dictadura, Ministerio de Defensa, Presidencia de la Nación Argentina, pueden ser consultadas completas en: www.archivosabiertos.com.ar.

${ }^{7}$ La mayor parte de estos documentos reservados pertenecen al archivo personal de la autora, y no se encuentran en ningún repositorio documental conocido.

${ }^{8}$ Marcos Novaro y Vicente Palermo, La dictadura militar 1976/1983. Del golpe de Estado a la restauración democrática, Buenos Aires, Paidós, 2003.
} 
básicos del proceso", la totalidad del Poder Ejecutivo fue subordinado a la JM: "los gobiernos nacional y provincial ajustarán su acción a los objetivos básicos que fijó la Junta Militar, al presente estatuto y a las Constituciones nacional y provinciales en tanto no se opongan a aquéllos"10. Ante la ausencia de mecanismos electorales, era el Ejecutivo Nacional el que designaba a los gobernadores provinciales, mientras que estos, a su vez, designaban a los intendentes municipales ${ }^{11}$.

Las funciones políticas que debían cumplir los gobernadores provinciales y los intendentes municipales también fueron definidas por el Ejecutivo Nacional ${ }^{12}$. En la III Reunión con los gobernadores, en 1977, el general Jorge Rafael Videla, Presidente de la Nación, y el general Albano Harguindeguy, ministro del Interior, definían las "bases filosóficas y prácticas de la trascendencia de la participación a nivel municipal"13. Los gobiernos provinciales debían mantener "una alta dosis de conocimiento de la realidad circundante (y) un diálogo permanente con los sectores representativos locales que, además de evitar el aislamiento, posibilite la recepción de aportes válidos para la gestión de las respectivas administraciones"14. Mientras que en el ámbito municipal, donde "la relación entre la autoridad y el ciudadano es más directa", debía promoverse la "participación (vecinal) en la realización de tareas ejecutivas (...) El fortalecimiento del régimen municipal y la participación de la civilidad en el gobierno comunal tendrán para nosotros un claro sentido democrático (...)"15. El municipio, tal como lo definía Albano Harguindeguy, era una "escuela de responsabilidad pública, de práctica republicana y transparencia en la acción de gobierno" $"$.

Esta diferenciación de funciones entre los distintos ámbitos de gobierno fue apuntalada por el reclutamiento diferenciado de funcionarios. En el provincial, los gobernadores militares fueron una abrumadora mayoría frente los civiles: más del $75 \%$ del

${ }^{9}$ Los Documentos básicos del proceso eran un conjunto de normas fundamentales que la dictadura se dio a sí misma como parte de sus extensas atribuciones soberanas, justificadas en la supuesta "situación de excepcionalidad" que vivía Argentina en 1976, algunos de los cuales fueron modificados con el correr del tiempo. Se trataba del Acta fijando el propósito y los objetivos básicos para el Proceso de Reorganización Nacional, el Acta para el proceso de reorganización nacional (PRN), la Proclama, las Bases para la intervención de las Fuerzas Armadas en el proceso nacional, el Estatuto para el proceso de reorganización nacional, el Reglamento para el funcionamiento de la Junta Militar, Poder Ejecutivo Nacional y Comisión de Asesoramiento Legislativo, la Sustitución del artículo $6^{\circ}$ del estatuto para el proceso de reorganización nacional, y la Ley de la Junta Militar introduciendo modificaciones al reglamento para el funcionamiento de la Junta Militar, Poder Ejecutivo nacional y Comisión de asesoramiento legislativo. Documentos básicos y bases políticas de las Fuerzas Armadas para el proceso de reorganización nacional, Junta Militar, República Argentina, Buenos Aires, 1980.

${ }^{10}$ Estatuto para el proceso de reorganización nacional, 24 de marzo de 1976, op. cit., p. 27.

${ }^{11}$ En noviembre de 1979, la provincia de Buenos Aires aprobó el decreto ley de municipalidades $\mathrm{N}^{\circ}$ 9448/79, que legalizaba el sistema de selección de intendentes establecido en 1976; Rodríguez, "Descentralización...", op. cit., p. 374.

${ }^{12}$ Sobre las diferentes funciones que debían cumplir los niveles de gobierno nacional, provincial y municipal durante la dictadura, véase Paula Canelo, "Construyendo elites dirigentes. Los gobernadores provinciales durante la última dictadura militar (Argentina, 1976-1983)", en Anuario del Centro de Estudios Históricos "Prof. Carlos S. A. Segreti", vol. 11, No 11, Córdoba, 2011, pp. 323-341.

${ }^{13}$ Comentario sobre el Documento plan nueva república, Secretaría General de la Presidencia, 1977, p. 8. Archivo personal de la autora.

${ }^{14}$ Diario La Nación, Buenos Aires, 16 de abril de 1977.

${ }^{15}$ Ibid.

${ }^{16}$ Diario La Nación, Buenos Aires, 2 de septiembre de 1977. 
total entre 1976 y 1983 y mayoría absoluta hasta $1981^{17}$. Pero los militares ocuparon solo un $10 \%$ de las intendencias (ciento setenta de un total de mil seiscientos noventa y siete), mientras que el restante $90 \%$ quedó en manos civiles ${ }^{18}$. De estos intendentes civiles, el 57\% (ochocientos setenta y ocho) pertenecía diferentes partidos políticos, como la Unión Cívica Radical, el Partido Justicialista (peronista), el Partido Demócrata Progresista, el Movimiento de Integración y Desarrollo, la Fuerza Federalista Popular, el Partido Demócrata Cristiano o el Partido Intransigente, mientras que el 43\% restante (seiscientos cuarenta y nueve) no poseía militancia política ${ }^{19}$.

El reclutamiento de civiles en las intendencias fue masivo, pero cuidadoso. El 10 de mayo de 1976, una directiva de la Presidencia de la Nación fue enviada al Ministerio del Interior con el propósito de establecer las "modalidades a seguir respecto de la designación de intendentes" ${ }^{20}$. Las pautas eran:

“a) honestidad en el desempeño del cargo o en sus antecedentes personales; b) idoneidad para la función; c) prestigio y representatividad en el medio donde deberá cumplir su cometido (...); Una vez confirmados o reemplazados los intendentes municipales, deberá informarse al Señor Presidente la nómina y extracción política de los funcionarios en servicio”²1.

Los intendentes eran piezas clave en el tendido de una red "capilar" de control político y vigilancia militar sobre la que se asentaba el poder de la dictadura militar. Los gobernadores buscaron designar en las intendencias a individuos con "estrecha vinculación con las asociaciones locales" y con "amplio reconocimiento en la comunidad" 22 ; en muchos casos, los intendentes del gobierno peronista, que habían sido electos en marzo de 1973, fueron confirmados en sus cargos por la dictadura ${ }^{23}$.

Las directivas del Ejecutivo nacional fueron bien recibidas por algunos mandatarios provinciales que hicieron de la "municipalización" y el "comunitarismo" 24 una política de Estado. Uno de ellos fue el gobernador de la poderosa provincia de Buenos Aires, el general Ibérico Saint Jean, que junto a James Smart, su ministro de Gobierno, procuraron gestar en territorio bonaerense una dirigencia local adicta, reclutada en los movimientos vecinalistas, mientras fortalecían el poder y la autonomía de los intendentes, transfirién-

\footnotetext{
${ }^{17}$ Sólo veinticuatro de los noventa y ocho individuos que ocuparon los ejecutivos provinciales entre 1976 y 1983 fueron civiles, y su incorporación comenzó, recién en 1981. Canelo, “Construyendo ...”, op. cit., p. 335 y ss.

${ }^{18}$ Los datos no son exactos, pero sí relativamente coincidentes en las diversas fuentes. Por ejemplo, en marzo de 1981, Albano Harguindeguy afirmaba que el $88 \%$ de las intendencias de todo el país estaban ocupadas por civiles, y un 12\% por militares; diario La Nación, Buenos Aires, 26 de marzo de 1981.

${ }^{19}$ Diario La Nación, Buenos Aires, 25 de marzo de 1979.

${ }^{20}$ Quiroga, op. cit., p. 86; Enrique Vazquez, La última. Origen, apogeo y caída de la dictadura militar, Buenos Aires, EUDEBA, 1985, p. 68.

${ }^{21}$ Ibid.

${ }^{22}$ González Bombal, Los vecinazos..., op. cit., p. 51; María de los Ángeles Yannuzzi, Política y dictadura. Los partidos políticos y el Proceso de Reorganización Nacional. 1976-1982, Rosario, Fundación Ross, 1996, pp. 90-91.

${ }^{23}$ Lvovich, "Burócratas...", op. cit., p. 414.

${ }^{24}$ González Bombal, Los vecinazos..., op. cit., p. 50 y ss; Rodríguez, “Descentralización...”, op. cit., pp. 373 y 376 .
} 
doles distintas funciones y servicios ${ }^{25}$. En abril de 1976, Ibérico Saint Jean dirigió a todos los intendentes de la provincia de Buenos Aires otra directiva que destacaba "la finalidad de propender el consenso y participación de toda la comunidad en la acción de gobierno", aunque "con absoluta prescindencia de connotaciones de carácter político"26.

No casualmente fueron Ibérico Saint Jean y James Smart, junto a Jorge Aguado, dirigente agropecuario y futuro gobernador de la provincia, quienes redactaron uno de los primeros documentos reservados que abordaron la "cuestión política" del proceso. Se trataba del texto Un nuevo ciclo histórico argentino: del proceso de reorganización nacional a la tercera república. Lineamientos para una estrategia nacional, de octubre de 1976.

En el documento, las preocupaciones por el nivel municipal estaban vinculadas con la "cuestión política" más amplia del gobierno militar. En primer lugar, con la decisiva problemática del llamado "Plan Político" del régimen, documento que debía ordenar la futura "institucionalización del país" y que el gobierno militar pretendía consensuar internamente primero para luego presentarlo ante la opinión pública argentina. En segundo lugar, con el problema de la gestación de la descendencia política del proceso, asociada con la idea de Movimiento de Opinión Nacional (MON), objetivo refundacional del régimen que era considerado una de sus garantías de éxito. Por último, con el desafío que representaban, para un gobierno autoritario muy apoyado sobre el terrorismo de Estado, tanto el control de la participación civil como la recreación del consenso social y la legitimación ${ }^{27}$.

El documento Un nuevo ciclo histórico argentino... consideraba necesario lograr la "comprensión" de los civiles en la primera etapa de gobierno del proceso, la que requería mayores "sacrificios", por lo que recomendaba desplegar "gestos de apertura" como "designaciones de embajadores, contactos del presidente con intelectuales, científicos, productores, etc." ${ }^{28}$. Sin embargo, la dictadura debía rechazar cualquier tipo de vínculo con la "dirigencia política preexistente":

"El tema central al que deberá responder el nuevo proyecto político es el de la vertebración de una nueva clase dirigente, suficientemente expresiva de la sociedad argentina actual y flexible para adecuarse a una realidad futura, así como inequívocamente identificada con la heredad tradicional y dispuesta a resistir hasta la victoria a la agresión marxista populista (...). Por lo tanto, las FF.AA. deberán evitar simultáneamente: el aislamiento respecto de la civilidad; la tentación del 'pacto' con la dirigencia civil preexistente" ${ }^{29}$.

\footnotetext{
${ }^{25}$ Rodríguez, “Descentralización...”, op. cit., p. 373 y ss.

${ }^{26}$ Municipalidad de Morón, Registro de Decretos y Resoluciones, (RDR), libro 111, expediente 1791 - I1976, $f^{\circ}$ 241, 5 de abril de 1976.

${ }^{27}$ Paula Canelo, El proceso en su laberinto. La interna militar de Videla a Bignone, Buenos Aires, Prometeo, 2008; Paula Canelo, "La politique sous la dictature argentine. Le Processus de réorganisation nationale ou la tentative inachevée de refonte de la société (1976-1983)", in Vingtième Siècle. Revue d'Histoire, N 105, Paris, janvier-mars 2010, pp. 81-92.

${ }^{28}$ Un nuevo ciclo histórico argentino: del Proceso de reorganización nacional a la tercera república. Lineamientos para una estrategia nacional, general Ibérico Sain Jean, octubre de 1976, sin paginar. Archivo personal de la autora.

${ }^{29} \mathrm{Ibid}$.
} 
El texto de Ibérico Saint Jean delineaba dos de los objetivos políticos refundacionales de la dictadura militar, cuya persecución sería muy conflictiva: la refundación de la elite dirigente argentina y la institucionalización del poder militar a partir de la creación de un nuevo órgano gubernamental de tipo tutelar, previa reforma de la Constitución Nacional $^{30}$. Inspirados por un profundo elitismo, los bonaerenses imaginaban la creación de un "consejo de la república", un ámbito de representación de intereses "(donde) las FF.AA. participarán (...) como custodios de los intereses específicos de la seguridad y el potencial de la Nación, disponiendo de un poder de veto respecto de iniciativas en que estimen vulnerados dichos intereses"31. Este "Consejo de la República" (o "Poder Corregidor" en la versión del civil Jaime Perriaux, como se verá más adelante), y la capacidad de la dictadura de resistir la "tentación" del pacto con los civiles, eran las garantías de que el proceso lograría evitar los "saltos al vacío" que habían hecho fracasar a las dictaduras militares anteriores, especialmente a la Revolución Argentina (1966-1973), antecesora del Proceso.

Poco después de que los bonaerenses redactaran su plan, el gobierno militar dio los primeros pasos hacia la presentación pública de su propuesta política. En enero de 1977 se conocieron las Bases para la intervención de las Fuerzas Armadas en el proceso nacional, que presentaban algunas proposiciones generales sobre los objetivos políticos del régimen militar:

“(...) la instauración de una verdadera democracia, auténticamente representativa, con plena vigencia de nuestros principios republicanos tradicionales, con un auténtico y efectivo federalismo, sustentadas por corrientes de opinión nacionales amplias y sólo urgidas por la grandeza del país y el bien común, basada en una sociedad unida, organizada y solidaria y con una economía vigorosa (...) es menester que la acción de las FF.AA. facilite en el futuro la formación de un movimiento de opinión nacional, vital y amplio, que admita a todos aquellos que deseen la verdadera grandeza del país y se sientan consustanciados con los postulados del gobierno nacional" 32 .

La vaguedad y las escasas precisiones operativas de las Bases para la intervención... ya mostraban los límites que encontraba el gobierno militar para consensuar sus propios objetivos políticos, en especial por las profundas contradicciones que atravesaban en ese plano a los elencos civiles y militares del proceso, como veremos. Progresivamente, el espacio de reflexión sobre la "cuestión política" del gobierno militar comenzó a ser mo-

${ }^{30}$ Sobre una reforma de la Constitución también avanzaba por entonces la dictadura chilena, que lograría implementarla en 1980; al respecto, véase Robert Barros, Constitutionalism and Dictatorship. Pinochet, the Junta and the 1980 Constitution, Cambridge, Cambridge University Press, 2002. La dictadura uruguaya convocó en noviembre de 1980 a un plebiscito de reforma constitucional que no obtuvo el apoyo esperado, por lo que el proyecto no prosperó; Yaffé, op. cit., p. 22. Por su parte, la dictadura argentina no llegó nunca a establecer los acuerdos mínimos que le permitieran reformar la Carta Magna, tal como mostramos en Canelo, El proceso..., op. cit., 154.

${ }^{31}$ Un nuevo ciclo histórico argentino: del proceso de reorganización nacional a la tercera república. Lineamientos para una estrategia nacional, general Ibérico Sain Jean, octubre de 1976, sin paginar. Archivo personal de la autora.

${ }^{32}$ Bases para la intervención..., op. cit., enero de 1977, Documentos básicos y bases políticas..., op. cit., p. 13 y ss. Archivo personal de la autora. 
nopolizado por algunas fracciones internas cuyo poder e influencia fueron promovidos por coyunturas específicas.

La fracción "dura" del Ejército gozó de enormes espacios de poder durante los primeros años del régimen, por la importancia que en la agenda gubernamental tenía la feroz política represiva implementada. Esta fracción estaba integrada por los generales que comandaban los cuerpos de Ejército a partir de los que se zonificó todo el territorio argentino y se organizó el terrorismo de Estado ${ }^{33}$. Eran fervorosos promotores de la "lucha antisubversiva", a la que concebían como objetivo excluyente del régimen, y rechazaban cualquier acercamiento con las organizaciones políticas. Profundamente antiperonistas, estos generales eran herederos del corporativismo que había impregnado numerosas políticas implementadas por el Onganiato, durante los primeros años de la Revolución Argentina ${ }^{34}$.

A fines de 1976, la influencia de esta fracción "dura" se concretó con la creación de un ministerio de planeamiento, a cuyo frente fue designado uno de sus miembros más paradigmáticos, el general Ramón Genaro Díaz Bessone, que había ocupado cargos en el área de planeamiento durante la dictadura previa. Una de las funciones fundamentales del nuevo ministerio era redactar el Plan Político del régimen, ahora bautizado Proyecto nacional, entre cuyos objetivos se encontraba el de lograr la legitimación del régimen militar: el texto se proponía " 1.3 . Servir de base para la consulta y la recepción de aportes de la comunidad a través de sus figuras y entidades más representativas y calificadas (...) 1.4. Predisponer las condiciones para el consenso y la adhesión activa al Proyecto" 35 .

El documento resumía los principios políticos fundamentales del imaginario corporativista y establecía las bases para lo que denominaba "Nueva República", concepto con fuertes connotaciones ideológicas que refería directamente a las tradiciones del nacionalismo y del corporativismo argentinos ${ }^{36}$.

El Proyecto nacional compartía con el plan de Ibérico Saint Jean el desprecio por la representación político-partidaria, que debía ser reemplazada por la de las "entidades

\footnotetext{
${ }^{33}$ Se trataba de los generales: Carlos Guillermo Suárez Mason (Cuerpo I), Ramón Genaro Díaz Bessone (Cuerpo II), Luciano Benjamín Menéndez (Cuerpo III), Santiago Omar Riveros (Institutos militares) y Osvaldo Azpitarte (Cuerpo v); sus segundos comandantes y jefes de Estado Mayor, los generales: Acdel Vilas, Fernando Santiago, Carlos Dalla Tea y Jorge Olivera Rovere. A la fracción “dura” también pertenecía, por ejemplo, el general Ramón Camps, Jefe de la Policía de la provincia de Buenos Aires, paradigmático exponente del terrorismo de Estado.

${ }^{34}$ Sobre la importancia alcanzada por los corporativistas durante la Revolución Argentina, véase Gabriela Gomes, "Las trayectorias políticas de los funcionarios nacional-corporativistas del Onganiato", ponencia presentada durante la jornada "Recuperando trayectorias intelectuales en el Estado. Argentina en la segunda mitad del siglo xx", Buenos Aires, Universidad Nacional de General Sarmiento, 2013, s/d y Guillermo O’Donnell, El Estado burocrático autoritario 1966-1973. Triunfos, derrotas y crisis, Buenos Aires, Prometeo, 2009 , p. 125 y ss. Sobre la continuidad entre los corporativistas del Onganiato y los del proceso, véase Paula Canelo, "Los desarrollistas de la 'dictadura liberal'. La experiencia del Ministerio de Planeamiento durante el Proceso de Reorganización Nacional en la Argentina”, en Anos 90 , vol. 19, No 35, Porto Alegre, julio de 2012, pp. 169-190.

35 Proyecto Nacional, Ministerio de Planeamiento, 25 de mayo de 1977, pp. 3-4. Archivo personal de la autora.

${ }^{36}$ Véase infra la crítica que a otro plan de los "duros", el Plan Nueva República, realizaron los miembros de la Secretaria General de la Presidencia de la Nación en el texto reservado Comentario sobre el documento Plan Nueva República..., op. cit., p. 4.
} 
intermedias": tanto las entidades de "orden civil" como "la familia, las asociaciones, instituciones y entidades sociales", como las de "orden político", "las comunas, los departamentos, las provincias, las regiones, etc."37. Estas "entidades intermedias" debían transformarse en los canales del consenso y de la participación, dos de los "valores universales y permanentes sobre los cuales se ha constituido la Nación Argentina"38. De acuerdo con el Proyecto nacional, ambos valores se encontraban estrechamente vinculados: "el consenso es la conciencia de todos los miembros de la comunidad nacional de saber que participan en las decisiones fundamentales a través del sistema social y político, y que los logros nacionales los tienen como destinatarios finales", mientras que "la participación constituye una de las formas básicas de cohesión nacional"39.

El municipio era considerado por los corporativistas del Ministerio de Planeamiento como el ámbito fundamental de la participación de una "ciudadanía municipal", apolítica y de alcance local, basada en la "convivencia solidaria" entre vecinos. Debía ser reconocido como la "célula básica" de la "estructura política de la Nación", y debía ser convertido en "eje de la vida comunitaria y en el gran gestor de los intereses de la misma" 40 , ya que "la convivencia vecinal y la Comunidad de intereses y necesidades favorecen el desarrollo de una más auténtica solidaridad"41. Para ello, el plan de Ramón Díaz Bessone postulaba, en una primera "Etapa fundacional", "Renovar y fortalecer el régimen municipal a fin de asegurar la plena participación política y social de la comunidad en tal nivel, y convertir al municipio en base y escuela de auténtica democracia" ${ }^{\prime 2}$.

Repitiendo un signo característico de la mayor parte de estos planes reservados, el documento no daba precisiones instrumentales sobre cómo lograr los titánicos objetivos propuestos. Como "horizonte temporal" de la "Etapa fundacional" el Proyecto nacional proponía el "año 2000, por considerarse el lapso de veintitrés años que resta para alcanzarlo, como la unidad de tiempo correcta, para conjugar la necesidad de una visión realmente profunda, con la exigencia de mantener un criterio realista"43.

A pesar del casi nulo consenso que despertaron las propuestas políticas del Proyecto Nacional dentro del gobierno militar y de las Fuerzas Armadas ${ }^{44}$, los "duros" continuaron elaborando sus propuestas corporativistas. En mayo de 1977 vio la luz el Plan Nueva República, escrito por el general Jorge Olivera Rovere, secretario general del Estado Mayor del Ejército y ex $2^{\circ}$ Comandante del Cuerpo de Ejército I. El documento trazaba una "estrategia de política general" que constaba de tres etapas:

"1ra. Etapa: -Efectuar una convocatoria del pueblo (sic.) para la Unidad Nacional orientada a la consecución de los objetivos del PRN y encuadrada dentro de las siguientes pautas: -Mantenimiento de la supresión de la actividad política partidaria. (...) -Determinación de los propios interlocutores para el diálogo en todos los órdenes y niveles. (...) 2da. Etapa: -Iniciar la

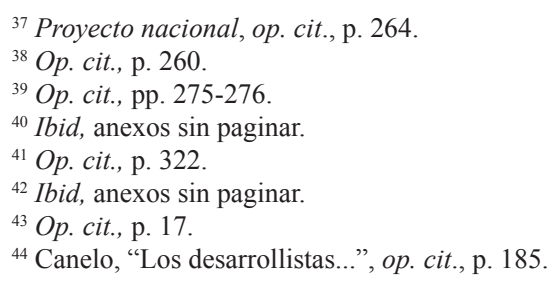


participación a nivel municipal y en otros cargos públicos de nivel similar. -Facilitar la actividad política no partidaria. (...) -Ampliar la posibilidad de diálogo. -Promoción de líderes (...) 3ra. Etapa: -Convocar a una Convención Constituyente. (...) -Institucionalizar los movimientos de opinión. -Sancionar los nuevos estatutos de los partidos políticos. -Realizar elecciones piloto a nivel municipal. - Realizar compulsas populares sobre grandes temas nacionales a través de referéndum. -Formulación del Plan Político. -Formulación y convalidación de reaseguros políticos y jurídicos para asegurar la continuidad del proceso" ${ }^{\text {"45. }}$.

El Plan Nueva República establecía que estas etapas debían desarrollarse en el lapso de doce a quince años, pero sin plazos prefijados; además, avanzaba en algunas precarias precisiones instrumentales, prácticamente ausentes de los planes de Ibérico Saint Jean y de Ramón Díaz Bessone. El municipio era el ámbito indicado, por ser el nivel más controlable, para la incorporación de civiles al gobierno y para la realización de futuras elecciones "piloto" desvinculadas de otros niveles.

PLAN NUEVA REPUBLICA

\begin{tabular}{|c|c|c|}
\hline PROCESO DE REORGANIZACION N A C I ONAL 12 A 15 A ÑOS \\
\hline $\begin{array}{r}\text { ASUN } \\
\text { CION }\end{array}$ & FASE REORDENAMIENTO INSTITUCIONAL & FASE CONSOLIDACION \\
\hline
\end{tabular}

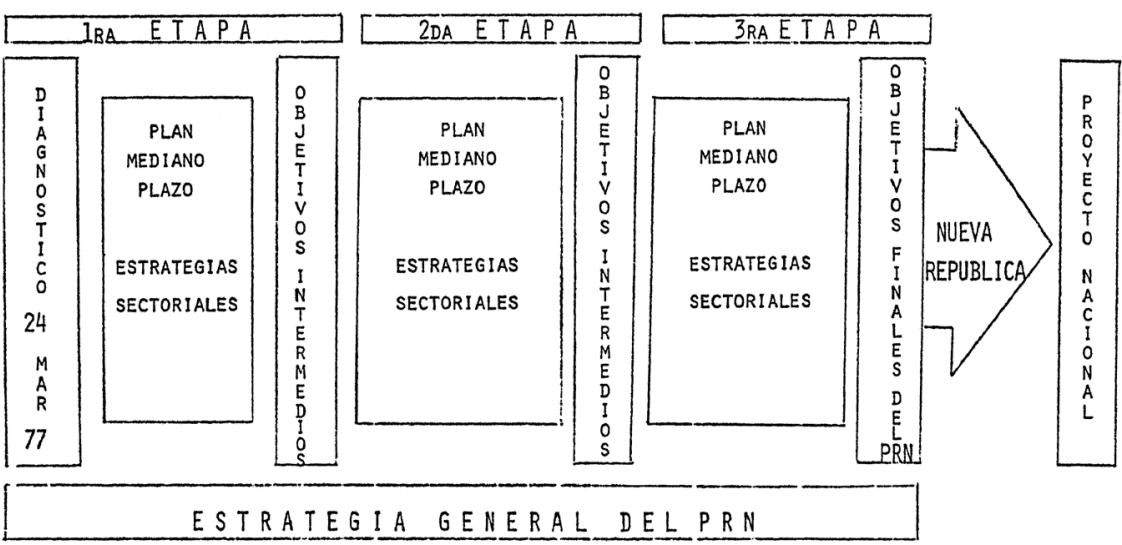

"Proceso de Reorganización Nacional - 12 a 15 años", en Plan Nueva República, Secretaría General del Estado Mayor General del Ejército, mayo de 1977, p. 15. Archivo personal de la autora.

Estos avances de los "duros" provocaron la reacción de otras fracciones políticas que controlaban otros espacios gubernamentales, como la de los "politicistas" del Ejército, que dominaban la poderosa Secretaría General de la Presidencia de la Nación a través del general José Rogelio Villarreal y de Ricardo Yofre, civil vinculado con la Unión Cívica

\footnotetext{
${ }^{45}$ Plan Nueva República, op. cit., pp. 8-9. Archivo personal de la autora.
} 
Radical. A diferencia de los "duros", los "politicistas" mantenían posiciones pragmáticas en el plano político: si lo que estaba en riesgo era el destino de la experiencia refundacional en su conjunto, el proceso podía resignar a algunos de sus objetivos, por ejemplo, el de la refundación de la elite dirigente argentina, por lo que resultaba viable mantener vínculos con las organizaciones políticas existentes ${ }^{46}$. En el documento reservado Comentario sobre el documento Plan Nueva República, los "politicistas" criticaron duramente el "nacionalismo"47 y "corporativismo" del plan de Olivera Rovere, afirmando que el texto solo era "un conjunto de aspiraciones que, sin una sistematización suficiente, no alcanzan a conformar ni un programa de gobierno ni un plan de acción política"48. El documento le dedicaba feroces y detalladas críticas a cada una de las Etapas del Plan Nueva República:

“2.5.2.1. Primera Etapa: (...) -Se considera que el primer inconveniente radica en que no se establece un plazo, aunque sea aproximado, para la duración de esta etapa. (...) -En tal sentido, ¿hasta cuando se ha de mantener la suspensión de la actividad política partidaria? (...).

2.5.2.2. 2a. Etapa: Para esta etapa, el Plán (sic.) Nueva República prevé el inicio de la participación civil a nivel municipal. Al respecto, cabe anotar que el 10 de mayo de 1976, el Señor Presidente remitió al Ministerio del Interior una directiva relacionada con las modalidades a seguir respecto a la designación de intendentes (que) dio lugar a la iniciación de la participación civil, en ese nivel gubernamental, desde el comienzo mismo del P.R.N. Asimismo, en la reciente reunión de gobernadores, tanto a través del Ministerio del Interior, como del Señor Presidente, se establecieron las bases filosóficas y prácticas de la participación a nivel municipal (...) -Tampoco se entiende en qué consiste la concreción de las estructuras orgánicas de los movimientos de opinión, ni qué son estos 'movimientos de opinión'.

2.5.2.3. 3a. Etapa: (...) - La eventualidad de efectuar elecciones piloto a nivel municipal, impone una gran prudencia. En tal sentido, se considera aventurado adelantar tal posibilidad, máxime, cuando a ésta se la dilata para una tercera etapa, cuya ubicación temporal debe efectuarse en relación a los 12/15 años en que se estima la culminación del Proceso. -Conforme al documento, la formulación del Plan Político se reserva para la parte final de la tercera etapa. Todo lo analizado hasta aquí, ¿no constituye un plan político?"49.

Los "politicistas" redactaron su propio plan en noviembre de 1977, en el documento reservado Plan de acción política de la propuesta de Unión Nacional. El trabajo se diferenciaba netamente de los documentos anteriores porque carecía de ambiciosas definiciones programáticas, y porque ni la creación del MON, ni la institucionalización de las Fuerzas Armadas como "cuarto poder", ni la participación comunitaria como "escuela de la democracia” encontraban lugar entre sus líneas. Su propósito era bien diferente:

${ }^{46}$ Canelo, El proceso..., op. cit., p. 163.

${ }^{47}$ Los miembros de la Secretaría General criticaban el concepto de "Nueva República", central también en el Proyecto Nacional, explicando: "-Tiene fuertes connotaciones ideológicas, no democráticas precisamente, vinculadas a las diversas corrientes del nacionalismo argentino. - A titulo de ejemplo, cabe señalar, que en la década del 30 los hermanos Julio y Rodolfo Irazusta junto a Ernesto Palacio y Manuel Carulla editaban una publicación política cuyo título era, precisamente, 'La Nueva República'. Asimismo, Marcelo Sanchez Sorondo rebautizó su periódico 'Azul y Blanco', en razón de haberse dispuesto su cierre, con el nombre de 'La Segunda República"'; Comentario sobre el documento Plan Nueva República, Secretaría General de la Presidencia, 1977, p. 4. Archivo personal de la autora.

${ }^{48}$ Op. cit., pp. 3-4, subrayado en el original, aquí cursivas.

${ }^{49} \mathrm{Op}$. cit., p. 7 y ss., subrayado y cursivas en el original, aquí cursivas. 
ofrecer un "conjunto sistematizado de procedimientos tendientes a conformar y concretar la Propuesta para la Unión Nacional"

El documento delimitaba dos grandes fases de ejecución. Durante la primera fase del Plan de acción..., entre noviembre de 1977 y marzo de 1979, el gobierno militar debía concentrarse en la "selección de interlocutores", en la definición de la "mecánica y objetivos del diálogo", y en el inicio del "segundo período presidencial de Videla" en diciembre de $1978^{51}$. Bajo la premisa fundamental de que "LEGITIMACIÓN significa CONSENSO"52, la dictadura debía buscar su "legitimación expresa por medio de un referéndum", luego del cual debía lograrse la "participación común en la tarea de gobierno" 53 de los civiles. A diferencia de los plazos de entre doce y veintitrés años de los "duros", los "politicistas" creían que el régimen debía acercarse a los civiles inmediatamente, darles participación en el ejercicio del poder y exigirles la convalidación de la "tarea realizada", sobre todo, la de los crímenes del terrorismo de Estado.

PLAN DE ACCION POLITICA - FASE PRIMERA

\section{Finalizaciôn tentativa: Marzo 1979}

DESARROLLO:

- Selección de interlocutores.

- Diălogo acerca de la Propuesta de Unión Nacional, es decir

- Aceptación de la Propuesta por vastos sectores.

- Iniciación, en Diciembre de 1978, del segundo periodo presidencial del Tte. Gral. Videla.

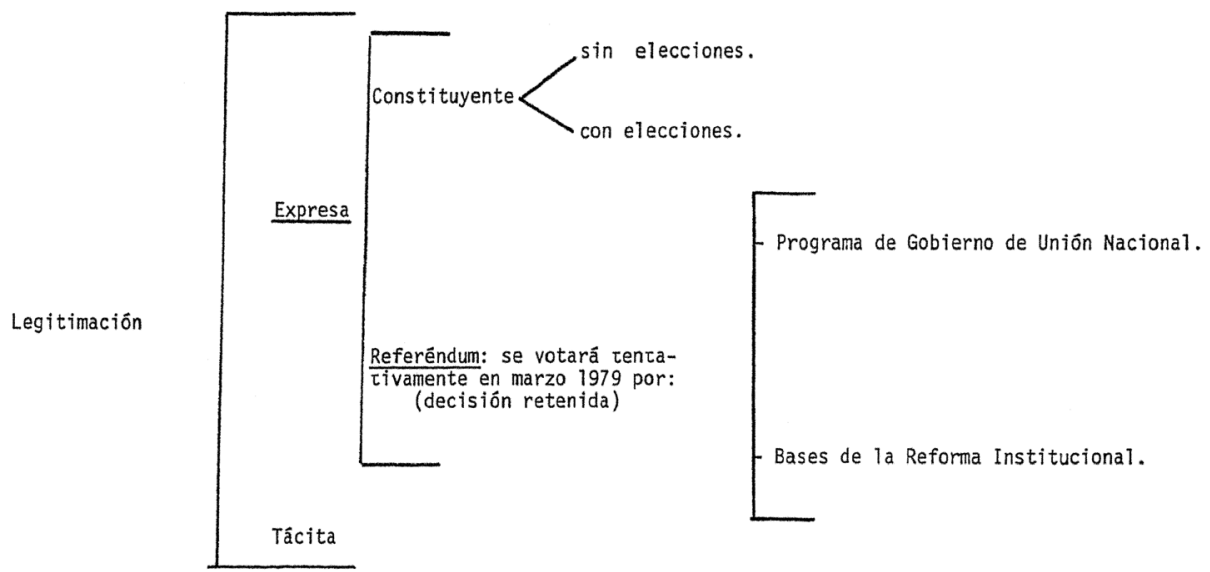

- Participación de civiles mediante su incorporación al gobierno.

"Plan de acción política - fase primera", Plan de acción..., op. cit., p. 41. Archivo personal de la autora.

${ }^{50}$ Plan de acción política de la propuesta de Unión Nacional. Secretaría General de la Presidencia, noviembre de 1977, p. 24. Archivo personal de la autora.

${ }^{51}$ Los miembros de la Secretaría General presionaban aquí por la "reelección" del general Jorge R. Videla para un segundo mandato presidencial.

${ }^{52}$ Plan de acción política..., op. cit., p. 25 y ss., mayúsculas en el original, aquí versales.

${ }^{53}$ Op. cit., p. 32, subrayado en el original, aquí cursivas. 
Durante la segunda fase del Plan de acción... (entre marzo de 1979 y el 1 de mayo de 1983) el gobierno debía implementar el "Levantamiento de la suspensión de la actividad política" en abril de 1980, la "Constitución y Reorganización de los Partidos Políticos" (nuevos o preexistentes) antes de julio de 1981, y la realización de "Elecciones para la Convención Constituyente" en diciembre de 1981, entre otras medidas ${ }^{54}$. Finalmente, los "politicistas" establecían que a principios de marzo de 1983 debían realizarse elecciones generales para permitir la "asunción del nuevo Presidente de la República y las demás autoridades por el período 1983-1987, el 1º de Mayo de 1983"55.

Los miembros de la Secretaría General recibían por entonces el aporte intelectual de otros altos funcionarios de la dictadura. Entre ellos, el de Américo Ghioldi, líder socialista y político profesional designado por la dictadura como embajador en Portugal, que en diciembre de 1977 le envió al general José R. Villarreal el documento reservado Plan de reforma política institucional. En él, Américo Ghioldi advertía que las Fuerzas Armadas, al haber asumido el ejercicio simultáneo de la "fuerza y la política" corrían un grave riesgo, por lo que no debía "demorarse innecesaria e injustificadamente el momento de la restitución de la Política a su función histórica. (...) A la hora actual, todo nuestro empeño debe estar contra el sistema populista, de bases fascista o hitleriana. Pero debemos evitar lo que Alberdi, trabajando con la realidad de sus días, llamó "exclusiones incivilizadas" "56.

El embajador proponía concretar un "acuerdo" entre las Fuerzas Armadas y la dirigencia política en torno a la selección de "un candidato a la Presidencia de la República que por los aportes de los firmantes asegure su mayoría", y a la realización de una "Reforma Institucional" ${ }^{57}$. Esta última debía incluir modificaciones en el nivel municipal:

“11) La Reforma establecerá una razonable y eficiente descentralización de conformidad con el sistema federal de gobierno, y la base municipal, fundamental como forma de participación democrática del pueblo. - Consolidará el régimen municipal. Los comicios municipales serán independientes de los comicios de carácter nacional y provincial. (...) -Instituirá un organismo nacional de estímulo, estudios y gestiones municipales y establecerá una Conferencia Nacional de Municipios (...) nuevo órgano social (para) ampliar el régimen de participación del pueblo"58.

Sin duda, uno de los colaboradores civiles más prominentes de la dictadura argentina fue Jaime Perriaux. En torno a este influyente abogado, exministro de Justicia de la Revolución Argentina y vicepresidente del grupo argentino-alemán Staudt \& Cia., dedicado a la venta de armas, se articularon dos de las agrupaciones civiles más activas en la producción ideológica adicta al régimen: la Sociedad de Estudios y Acción Ciudadana y el Grupo Azcuénaga ${ }^{59}$. En abril de 1978, Jaime Perriaux elaboró el documento reservado

${ }^{54}$ Plan de acción politica..., op. cit., pp. 34-38.

${ }^{55}$ Ibid.

${ }^{56}$ Plan de reforma politica institucional. Carta y propuesta política de Américo Ghioldi, embajador en Portugal, al general José Rogelio Villarreal, 22 de diciembre de 1977, pp. 5-6. Archivo personal de la autora.

${ }^{57}$ Op. cit., p. 5 y ss.

${ }^{58}$ Ibid., subrayado en el original, aquí cursiva.

${ }^{59}$ La Sociedad de Estudios y Acción Ciudadana había sido creada por Jaime Perriaux y era financiada por empresarios y banqueros; con más de mil miembros en todo el país, asesoraba al régimen redactando "planes de acción política y cultural". El Grupo Azcuénaga era un núcleo de intelectuales civiles de orientación libe- 

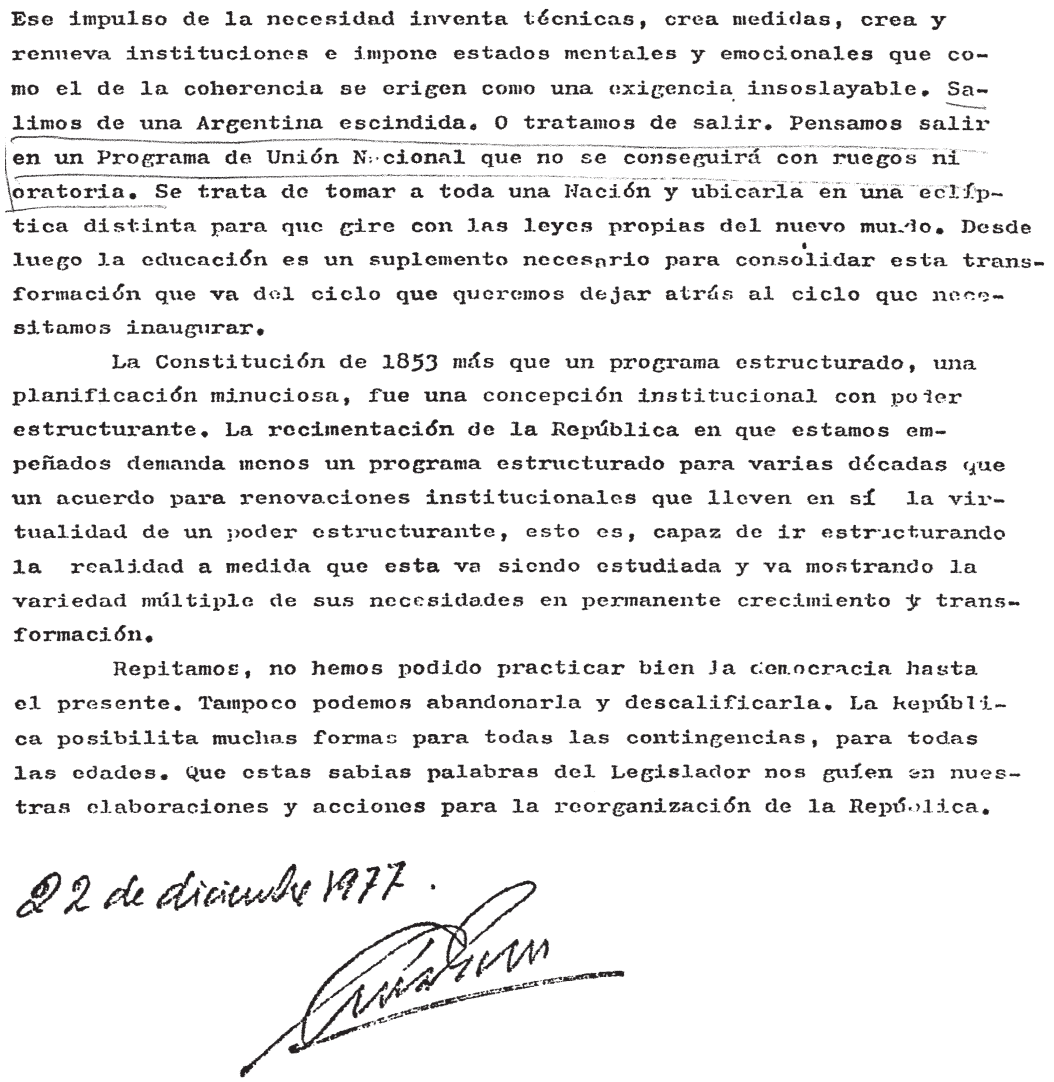

Plan de reforma política institucional. Carta y propuesta política de Américo Ghioldi, embajador en Portugal, al general José Rogelio Villarreal, 22 de diciembre de 1977, p. 12 (con firma de Ghioldi). Archivo personal de la autora.

denominado Propuesta política de Jaime Perriaux para el proceso de reorganización nacional que, a diferencia del hermetismo y la formalidad de otros documentos reservados, mostraba una evidente vocación didáctica sobre el auditorio militar.

ral-conservadora considerado el principal sostén civil de la dictadura argentina, por la influencia que tuvo su ideario sobre las orientaciones del régimen y por la cantidad de funcionarios que proveyó al gobierno dictatorial. Sergio Morresi, "El liberalismo conservador y la ideología del Proceso de Reorganización Nacional", en Sociohistóric, No 27, La Plata, primer semestre 2010, pp. 103-135; Martín Vicente, "Los intelectuales liberalconservadores argentinos y la última dictadura. El caso del Grupo Azcuénaga", en Kairos. Revista de Temas Sociales , año. 16, № 29, San Luis, mayo de 2012, s/d. 
De acuerdo con Jaime Perriaux, el gobierno militar debía aceptar "tres axiomas": "I) Ningún gobierno de las Fuerzas Armadas puede durar indefinidamente, II) Todo Gobierno de las Fuerzas Armadas es sucedido por un gobierno que, en una u otra medida, surge de algún tipo de consulta electoral, III) Nadie le saca a uno las castañas del fuego; se las tiene que sacar uno mismo"60. Además, advertía que una futura "consulta electoral" era no solo inevitable sino, además, peligrosa, dada la "altísima probabilidad de que se cuestione severamente, en un intento vengativo de establecer responsabilidades y aplicar graves sanciones, los métodos con que las Fuerzas Armadas alcanzaron el triunfo en la lucha contra la subversión" tamente indispensables" en cuatro planos:

“I) Una reforma institucional, en ciertos mecanismos tradicionales de la democracia, que dé a ésta mayor defensa contra sus dos grandes enemigos actuales: la infiltración y agresión marxista, y la demagogia (...) II) La creación de un nuevo gran movimiento político nacional (...) El gran medicamento histórico que tiene que tomar la Argentina es un triunfo claro sobre el peronismo en elecciones limpias. (...) III) La elaboración de un plan político en sentido estricto (que determine) cuáles son los sucesivos pasos que se vayan dando (...) IV) Un vasto programa de educación en sentido muy amplio" 62 .

Mediante la reforma institucional (también sugerida por el gobernador Ibérico Saint Jean y por el embajador Américo Ghioldi) debía crearse un "consejo de la república", un nuevo órgano de gobierno sin "origen electoral" ${ }^{63}$, que controlara a los otros poderes constitucionales (Ejecutivo, Legislativo y Judicial). Para Jaime Perriaux, debía tratarse de un "cuarto poder al que habría que llamar, quizás, Poder Corregidor": "será por un lado (...) lo que en la antigua ciudad griega de Heracles se llamaba "inspector de la unanimidad' y, por otro lado, algo así como una combinación de Banco Central y de Corte Suprema de la política (...) para evitar, precisamente, que mayorías electorales contingentes puedan poner en peligro la continuidad histórica de la Nación"

Los primeros documentos elaborados por militares y civiles muestran de qué forma comenzaba a articularse la "cuestión política" durante la última dictadura argentina. La cuidadosa selección de civiles para ocupar las intendencias, y la definición de las funciones que debían cumplir estos funcionarios mostraban que el nivel municipal era uno de los centros de atención del gobierno militar. El cual era nada menos que el instrumento político del complejo entramado "capilar" de vigilancia y control territorial y poblacional que era característico de la dictadura, y también el escenario de la participación de la "ciudadanía municipal", apolítica y de alcance local que el régimen deseaba promover.

Pero además, en torno a la "cuestión política" del proceso ya comenzaban a articularse tensiones internas: tales, por ejemplo, las que separaban a las posturas corporati-

\footnotetext{
${ }^{60}$ Propuesta política de Jaime Perriaux para el proceso de reorganización nacional, abril de 1978, p. I. Archivo personal de la autora.

${ }^{61}$ Ibid.

${ }^{62} \mathrm{Op}$. cit., vols. IV y v, p. 2.

${ }^{63}$ Op. cit., vol. v, p. 3 y ss.

${ }^{64} \mathrm{Op}$. cit., vol. v, p. 3 y ss.
} 
vistas de los "duros" del Ejército, herederos del corporativismo del Onganiato y partidarios fervorosos de la participación comunitaria, de las posturas más pragmáticas de los "politicistas" de la Secretaría General de la Presidencia de la Nación. La dictadura argentina comenzaba a tener dificultades para articular una "síntesis ideológica" entre las diferentes posturas existentes en su seno ${ }^{65}$.

Asimismo, en varios de los textos se plasmaban dos de las preocupaciones más profundas que atravesaban al gobierno militar en particular, y a las Fuerzas Armadas en general: la posible condena de los civiles sobre las aberraciones cometidas por los militares en la represión, y el riesgo de perder la histórica oportunidad de refundación que se les presentaba. En este plano uno de los objetivos más importantes era concretar una reforma institucional que consagrase al poder militar como nuevo órgano constitucional, clausurando de una vez por todas el largo ciclo de alternancia cívico-militar argentino abierto en 1930 .

\section{LOS PROCESOS DE COMPATIBILIZACIÓN, LAS BASES POLÍTICAS DEFINITIVAS Y EL “DIÁLOGO” CON LOS CIVILES}

Tras el fracaso del Proyecto nacional... como propuesta institucional, el gobierno militar sometió al Plan Político a la metodología de "compatibilización" característica de los procesos de toma de decisiones de la dictadura argentina. Esta metodología era consistente con la elevada fragmentación del poder derivada del reparto tripartito por el cual las Fuerzas Armadas se habían distribuido el conjunto de los cargos gubernamentales y estatales, y con la profunda fragmentación política del frente militar. Así, entre los primeros meses de 1977 y mediados de 1978 cada rama de las Fuerzas Armadas por separado desarrolló una primera etapa de "compatibilización intrafuerzas" que debía producir tres planes políticos parciales. Una vez concluida esta etapa, estos tres documentos debían ser sometidos a una segunda etapa de "compatibilización interfuerzas", de la que debía surgir el Plan Político definitivo que la JM presentaría a la opinión pública argentina ${ }^{66}$.

La Armada estaba muy interesada en rápidas definiciones, dadas las aspiraciones presidenciales de su Comandante en Jefe, el almirante Emilio Massera, uno de los exponentes más paradigmáticos de la represión, que mantenía un fuerte liderazgo sobre la fuerza ${ }^{67}$. Así, la Armada fue la primera en concluir la compatibilización interna, de la que surgió, en octubre de 1977, el documento Consideraciones sobre el proceso de institucionalización y el Movimiento de Opinión Nacional.

\footnotetext{
${ }^{65}$ Esta "síntesis ideológica" ha sido destacada como uno de los rasgos fundamentales de la exitosa experiencia de "municipalización" de la dictadura chilena. Véase Verónica Valdivia Ortiz de Zárate, "La alcaldización de la política: los municipios en la dictadura pinochetista", en Verónica Valdivia Ortiz de Zárate, Rolando Álvarez Vallejos y Karen Donoso Fritz, La alcaldización de la política. Los municipios en la dictadura pinochetista, Santiago, LOM Ediciones, 2012, p. 13. Volveremos sobre esta cuestión en las conclusiones.

${ }^{66}$ Canelo, El proceso..., op. cit., p. 88.

${ }^{67}$ Op.cit., p. 78 y ss.
} 
Los marinos recomendaban avanzar en el "Proceso de Institucionalización" a través de dos líneas de acción. La primera era "implementar una salida condicionada mediante la creación de un M.C. ${ }^{68}$ o partido político"69, un nuevo "movimiento de opinión, vital y amplio". Esta era, a criterio de la fuerza, "la mejor alternativa (para que el P.R.N.) se herede a sí mismo"70, y también, seguramente entendían, la que mejor posibilitaría la proyección del liderazgo de Emilio Massera hacia la política profesional ${ }^{71}$. La segunda vía era desarrollar una institucionalización "gradual" o "escalonada" desde el nivel municipal, considerado también por los marinos como posible "observatorio" de la apertura política, dado que, afirmaban, se trataba del nivel "más simple" para evaluar "el grado de aceptación social” del Proceso. Para ello el gobierno militar debía:

“(...) $4^{\circ}$ Dedicar la atención que requiere la reorganización de la administración del gobierno municipal, que sería la primera etapa y ejemplo para las sucesivas (...). $6^{\circ}$ Seleccionar provincias o áreas 'piloto' para realizar la experiencia o transitar los primeros pasos de la normalización (...) Permite evaluar el grado de aceptación y adhesión que recibe el PP $^{72}$ del P.R.N. a través de las sucesivas elecciones y valorar su posibilidad de herencia en el marco nacional"'73.

Ya en 1977 los marinos parecían advertir que la extrema concentración del poder político y gubernamental característica del Proceso, apoyada además en la más brutal represión, habían vuelto a la opinión pública argentina, principal blanco de la acción refundacional, una verdadera "caja negra". En otros términos, el régimen difícilmente podía conocer y evaluar la "recepción" social de sus políticas de legitimación, ni los efectos concretos de su acción disciplinadora y refundacional ${ }^{74}$. Para la Armada, el nivel municipal era el espacio propicio para abrir en forma progresiva y controlada la "caja negra" y observar el "grado de adhesión" alcanzado por el proceso.

El Ejército finalizó su documento en marzo de 1978, las Bases políticas del Ejército para el proceso de reorganización nacional. Las recomendaciones de la fracción "politicista" sobre la necesidad de delimitar plazos e instrumentos de acción fueron ignoradas en el documento definitivo de la fuerza ${ }^{75}$. En el apartado "plan de acción político" se recomendaba "Efectuar la apertura política (...) gradualmente a través de subetapas

${ }^{68} \mathrm{MC}$ : Movimiento cívico.

${ }^{69}$ Consideraciones sobre el proceso de institucionalización y el Movimiento de Opinión Nacional. Documento de trabajo, Armada Argentina, octubre de 1977, p. 14. Archivo personal de la autora.

${ }^{70}$ Ibid.

${ }^{71}$ En agosto de 1981, ya alejado de la Comandancia de la Armada, Emilio Massera lanzó un movimiento político propio, el Movimiento Nacional para el Cambio, integrado por militares, exfuncionarios del proceso y dirigentes políticos, y exdirigentes de corporaciones empresarias; Canelo, El proceso..., op. cit., p. 114.

${ }^{72}$ PP: Plan Político.

${ }^{73}$ Consideraciones sobre el proceso de institucionalización..., op. cit., p. 21.

${ }^{74}$ Este vínculo particular característico de los regímenes autoritarios ha sido trabajado por Oscar Oszlak, "Políticas públicas y regímenes políticos: reflexiones a partir de algunas experiencias latinoamericanas", en Estudios CEDES, vol. 3, No 2, Buenos Aires, 1980, s/d.

${ }^{75}$ Los "politicistas" de la Secretaria General renunciaron a sus cargos a fines de 1978, momento en el que también se profundizó la influencia de la política económica como instrumento refundacional del gobierno militar; Canelo, El proceso..., op. cit., p. 153. 
escalonadas", que dependieran del cumplimiento de determinados objetivos y "no de la aplicación de rígidos calendarios o cronogramas" $"$.

El Ejército le otorgaba al nivel municipal una gran importancia, por tratarse del locus de la "participación vecinal" "en el progreso material, moral y cultural de su ciudad", y en la "solución de los problemas que lo afectan":

“(...) h. Régimen municipal. El objetivo será renovar y fortalecer el régimen municipal a fin de asegurar la plena participación política y social de la comunidad a ese nivel (...) Se instaurará un régimen municipal conforme a las siguientes bases: 1) Establecimiento de un sistema de contralor y garantías jurisdiccionales que permitan afianzar un efectivo gobierno municipal. 2) Participación del vecindario en el progreso material, moral y cultural de su ciudad. 3) Descentralización de actividades a fin de liberar las energías creadoras del ciudadano y comprometer su responsabilidad en la solución de los problemas que lo afectan"77.

Los generales coincidían con los marinos en la necesidad de crear un movimiento de opinión y de avanzar progresivamente hacia la normalización institucional desde el "laboratorio" del nivel municipal. Durante la primera subetapa del "plan de acción político" propuesto, llamada "de estructuración de un MON, sin actividad política partidaria", el proceso debía "Estructurar un movimiento cívico-militar, suprapartidario y suprasectorial, consustanciado con los grandes objetivos nacionales implementados por las FFAA" "78. En la última subetapa, llamada "de transición con gobierno cívico-militar", el "retorno a la normalidad constitucional" debía ser "escalonado, en forma ascendente, hasta finalizar en el nivel nacional, sin que ello excluya la selección de provincias o áreas 'piloto' para realizar las primeras experiencias en el accionar político"79.

La Fuerza Aérea concluyó su compatibilización interna en julio de 1978. El documento reservado Bases políticas para la reorganización nacional fue redactado por la Secretaría General de la Fuerza, a cuyo frente se encontraba el brigadier Basilio Lami Dozo. En el texto el municipio era considerado el ámbito en el que debía hundir sus "raíces políticas" "una democracia eficiente y responsable", desde el cual debía proyectarse la "dirigencia natural" y donde la misma debía relegitimarse periódicamente. Los brigadieres postulaban los siguientes "Criterios rectores":

“(...) - Que la filosofía política que orienta el Plan, debe asegurar la instauración de una democracia estructurada sobre la base de un sistema de elección indirecta para los cargos ejecutivos, con excepción de los intendentes para los pequeños municipios, y directa para los cargos legislativos, buscando con ello que el votante decida por quién conoce y valora políticamente en su ámbito local. (...) -Que se instaure un sistema electoral que asegure la formación de una democracia eficiente y responsable que tenga sus raíces políticas en el municipio desde donde deben proyectarse los dirigentes naturales a los ámbitos políticos provinciales y nacionales;

${ }^{76}$ Bases políticas del Ejército para el proceso de reorganización nacional, Comando en Jefe del Ejército, marzo de 1978, pp. 3-11. Archivo personal de la autora.

${ }_{77}$ Op. cit., pp. 11-12, subrayado en el original, aquí cursivas.

${ }^{78}$ Op. cit., pp. 5-11, subrayado en el original, aquí cursivas.

${ }^{79} \mathrm{Op}$. cit., pp. 7-11 y ss., subrayado en el original, aquí cursivas. 
con un sistema de reelecciones que dificulte el caudillismo y obligue a una recurrencia periódica ante el ámbito local para la recalificación política (...)" ${ }^{\prime 80}$.

Para los brigadieres, la legitimidad de los "dirigentes naturales" del MON era local y debía descansar en el contacto directo con el votante y con sus problemas cotidianos. Estos líderes, potencialmente proyectables a las escenas provincial y nacional, "debían ser sometidos a la previa prueba de su capacidad electoral", para lo que se recomendaba “realizar primero una elección 'piloto' de ámbito municipal, con candidatos independientes (...). De allí saldrá una nómina de interlocutores válidos, con los cuales será posible fundar la o las fuerzas políticas (que competirán luego en elecciones provinciales y nacionales) (...) Por este sistema el ciudadano vota solamente por lo que conoce: al mejor de los candidatos locales. (...) Esta primera ronda de elecciones municipales se hará, a su vez en forma escalonada (2/3 años) para una mejor vigilancia" ${ }^{\prime}$.

\subsection{Organización Jerárquica de las Instituciones al Término del \\ Proceso de Reorganización Nacional}

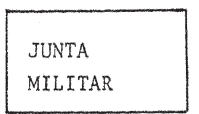

Pre-Existente
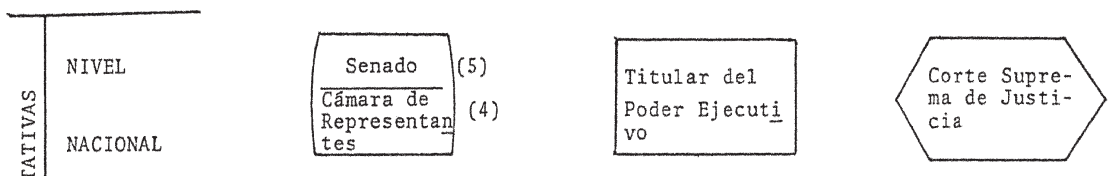

(7)

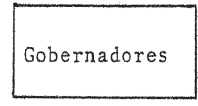

(6)

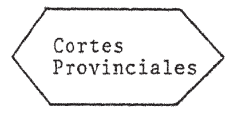

Pre-Existente
(2)

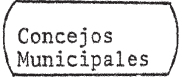

(3)

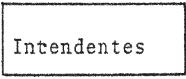

(1)

Los numeros entre paréntesis indican la cronología de su aparición en la escena institucional.

“Organización Jerárquica de las Instituciones al Término del Proceso de Reorganización Nacional”, en Bases políticas para la reorganización nacional, Documento de trabajo, Fuerza Aérea Argentina, 26 de julio de 1978, p. 46. Archivo personal de la autora.

\footnotetext{
${ }^{80}$ Bases políticas para la reorganización nacional, Documento de Trabajo, Fuerza Aérea Argentina, 26 de julio de 1978, p. 2. Archivo personal de la autora.

${ }^{81}$ Op. cit., pp. 35-37.
} 
Los planes institucionales generados durante la "compatibilización intrafuerzas" mostraban los esfuerzos que realizaban las Fuerzas Armadas por avanzar en la definición del Plan Político del Proceso, y también las dificultades por establecer consensos al respecto. Por ejemplo, si bien la necesidad de crear un MON era un principio compartido, la Armada lo concebía como una fuerza que vehiculizara el ascenso del liderazgo de Emilio Massera a la escena electoral nacional, mientras que la Fuerza Aérea creía más conveniente reclutar "dirigentes naturales" surgidos del nivel municipal y legitimados en el ámbito local. Además, si bien la importancia de fortalecer al municipio también era compartida, el Ejército y la Fuerza Aérea proponían fomentar el desarrollo de una "ciudadanía municipal" de alcance local, basada en la participación comunitaria y las redes de vecinazgo, mientras que la Armada la concebía como mero instrumento de "testeo" del consenso alcanzado por el proceso.

La finalización de la "compatibilización intrafuerzas" de los planes coincidió con el inicio de una nueva etapa de gobierno de la dictadura. En julio de 1978, el Proceso dio por finalizada la "situación de excepción", y separó los cargos de Presidente de la Nación y miembro de la JM, que fueron asumidos respectivamente por el general Jorge R. Videla y por el general Roberto Viola. La nueva etapa traía consigo nuevos desafíos para el gobierno militar. Por un lado, la anunciada finalización de la fase más cruda de la "lucha antisubversiva" amenazaba con debilitar los criterios de legitimación del régimen militar, que a diferencia de otros pares latinoamericanos (como, por ejemplo, el chileno) descansaba sobre todo en la "acción antisubversiva" de las Fuerzas Armadas ${ }^{82}$. Por otro lado, la dirigencia política comenzó a ocupar en forma progresiva la escena pública, publicando en agosto dos documentos muy críticos de la política económica del gobierno militar $^{83}$. La aceleración de los tiempos políticos, tanto internos como externos, recomendaba avanzar en la segunda etapa de "compatibilización interfuerzas" de los tres documentos parciales, de la que debía surgir el Plan Político definitivo.

La JM actuó en consecuencia aprobando en septiembre de 1978 las Pautas de la Junta Militar al Poder Ejecutivo Nacional (para el ejercicio de la acción de gobierno 1979/81) ${ }^{84}$, donde el Plan Político y el nivel municipal tenían gran importancia. Los comandantes establecían que el primero debía ser "emitido a la brevedad" y que frente a la reactivada dirigencia política el Presidente debía: "1. 1. Desalentar inequívocamente toda expectativa reivindicatoria de aquellos dirigentes políticos que no puedan brindar un aporte positivo a la marcha del Proceso. 1.2. Mantener el receso político de las estructuras partidarias. 1.3. Asegurar que la participación progresiva de elementos civiles en la función pública (...) se realice sobre personas de probada capacidad (...) y que adhieran a los postulados del Proceso (...)"85. En cuanto al régimen municipal, la JM exhortaba a "2.5. Revitalizar las instituciones municipales, favoreciendo la participación

\footnotetext{
${ }^{82}$ En efecto, el menor peso de la "amenaza subversiva" en el caso chileno, en comparación con el caso argentino, ha sido considerado como un elemento clave para entender la mayor consistencia del proyecto político de la experiencia pinochetista; Valdivia Ortiz de Zárate, "La alcaldización...", op. cit., p. 20.

${ }^{83}$ Diario La Nación, Buenos Aires, 20 de agosto de 1978.

${ }^{84}$ Pautas de la Junta Militar al Poder Ejecutivo Nacional (para el ejercicio de la acción de gobierno 1979/1981), Acta No 75, 7 de septiembre de 1978, en Actas de la dictadura, tomo 3, p. 62 y ss.

${ }^{85}$ Op. cit., p. 62.
} 
del vecindario en la gestión, aumentando la calificación política-técnica de sus funcionarios, fortaleciendo financieramente a las comunas y redimensionándolas de acuerdo a la realidad de las estructuras urbanas" $"$.

Luego de la renovación completa de la JM, finalizada durante los primeros meses de $1979^{87}$, se acordó un mecanismo de trabajo para la "compatibilización interfuerzas" del Plan Político en varias etapas, la última de ellas entre los miembros de la $\mathrm{JM}^{88}$. Sin embargo, el debate concreto en el seno del máximo órgano de gobierno se inició recién un año después, luego de la visita al país de la Comisión Interamericana de Derechos Humanos de la OEA en septiembre de 1979, acontecimiento de extrema importancia política para la dictadura que desplazó al Plan Político de la agenda de la JM. La peligrosidad que por entonces representaba el avance del frente de los derechos humanos comenzaba a transformar decididamente las prioridades gubernamentales.

En diciembre de 1979 se reanudó el debate y la JM comenzó a tratar un documento de trabajo secreto denominado Bases Políticas, que incluía las llamadas Bases instrumentales para la acción política de uso exclusivo de la Junta Militar, y que se proponían nada menos que "Establecer las bases para la institucionalización política de la Nación"89. Pero lejos de retomar las numerosas recomendaciones de los ya múltiples documentos políticos, la JM se limitó a repetir los mismos imprecisos postulados que en enero de 1977 habían inspirado las Bases para la intervención de las Fuerzas Armadas en el proceso nacional.

La única novedad de estas nuevas Bases era que en las mismas la JM definía las llamadas "premisas básicas no negociables" con los civiles, a saber:

"1.2.1. La convalidación de todo lo actuado en la lucha contra la subversión e impedir todo revisionismo sobre los mismos (sic.). 1.2.2. El resguardo debido de la estabilidad política futura de la Nación, asegurando la efectiva intervención institucionalizada de las Fuerzas Armadas en el gobierno y su competencia en la toma de decisiones para la conducción estratégica nacional, la seguridad nacional y la defensa de la Constitución nacional ${ }^{90}$. 1.2.3. La competencia de la J. M. para disponer inhabilitaciones políticas de personas u organizaciones, hasta el término del PRN. 1.2.4. La vigencia de los Documentos Básicos del PRN, hasta la finalización del mismo"91.

\footnotetext{
${ }^{86}$ Pautas de la Junta Militar al Poder Ejecutivo Nacional..., op. cit., p. 64.

${ }^{87}$ La JM que había ocupado el poder en marzo de 1976 se fue renovando progresivamente: luego de que Roberto Viola reemplazó a Jorge R. Videla, en septiembre de 1978 el almirante Armando Lambruschini reemplazó a Emilio Massera, y en enero de 1979 el brigadier Rubens Graffigna sucedió a Orlando Agosti.

${ }^{88}$ Acta $N^{\circ} 86,1$ de marzo de 1979, en Actas de la Dictadura, tomo 3, p. 165.

${ }^{89}$ Bases instrumentales para la acción política de uso exclusivo de la Junta Militar, Acta $\mathrm{N}^{\circ} 122,5$ de diciembre de 1979, Actas de la Dictadura, tomo 3, p. 286.

${ }^{90}$ La institucionalización del poder militar consistía en "asegurar su representación en el más alto nivel de gobierno, como así también en todo el esquema de la conducción superior de la Nación" una vez finalizado el proceso. Esta representación debía alcanzar cuatro modalidades: la intervención de los Comandantes en Jefe en las reuniones del gabinete nacional en "carácter de Secretarios de Estado"; el establecimiento de un sistema nacional de planeamiento y de un consejo de seguridad integrado por los comandantes en Jefe, el Presidente de la Nación y el ministro de Defensa, para tomar decisiones de Conducción Estratégica Nacional y de Seguridad Nacional; la modificación de la Ley para el Personal Militar y su reglamentación, en lo relativo a la designación de los comandantes en Jefe; y el mantenimiento de los delegados de los comandos en Jefe de las Fuerzas Armadas en los Ministerios Nacionales, en la Sindicatura de las Empresas del Estado y ante el Congreso Nacional; Acta No 122, 5 de diciembre de 1979, Actas de la dictadura, tomo 3, pp. 294-295.

${ }^{91}$ Op. cit., p. 286.
} 
He aquí que, pese a los precarios consensos existentes en el frente militar, en el mismo se había consolidado un puñado fundamental de objetivos "innegociables" cuya obtención sí inspiraba un sólido y extendido acuerdo. Estos objetivos serán los ítems fundamentales de todos los futuros (y fallidos) intentos de diálogo y concertación del gobierno militar con los civiles, y tendrán absoluta prioridad frente a cualquier otro objetivo político del proceso.

En estas Bases instrumentales para la acción política..., la JM proyectaba la sucesión de cuatro etapas de institucionalización, algunas con plazos definidos. La primera etapa, de "Consolidación del MON y apoyo al MC en coincidencia con el PRN", debía iniciarse el "19 DIC 79" con la presentación pública de las Bases definitivas; la segunda implicaba la "Recomposición del sistema de partidos políticos", "A partir 2do. Semestre 1980"; la tercera etapa presumía la "Transferencia gradual del gobierno, en el nivel provincial y municipal", sin precisiones sobre los plazos; y la cuarta, momento de "Instaurar el sistema político en el orden nacional", debía iniciarse "en el momento oportuno" ". Finalmente, el documento establecía las "Bases para el diálogo" con "las dirigencias política, económica, empresarial, factores de poder, etc.", que debía permitir "seleccionar grupos de apoyo, promoviendo y dinamizando un Movimiento de Opinión Nacional y su consecuente Movimiento Cívico identificado con el Proceso"93.

El plan político definitivo del gobierno militar, bautizado Bases políticas de las Fuerzas Armadas para el proceso de reorganización nacional, fue aprobado por la JM el 19 de diciembre de 1979. El extensísimo documento presentaba, en primer lugar, "bases doctrinarias", aquel conjunto de principios generales que se habían mantenido invariables desde 1977: que "el régimen representativo, republicano y federal (...) es el procedimiento insustituible para la organización política de nuestra sociedad"; o que el apoyo del "sistema político" debían ser "corrientes de opinión canalizadas por medio de grandes partidos políticos caracterizados por la adhesión sin reservas a los principios fundamentales contenidos en la Constitución Nacional", etcétera ${ }^{94}$.

En segundo lugar, las "bases programáticas" postulaban "ideas para cada área de gobierno", acerca de la separación de funciones entre las mismas. Allí se destacaba al nivel municipal como el lugar privilegiado de la participación civil: "El Gobierno municipal (...) Alentará la efectiva participación de los vecinos en la gestión y dispondrá de suficientes recursos humanos y técnicos para constituirse en la eficiente base y escuela formativa del ciudadano" $" 95$.

Por último, en las "bases instrumentales" se anunciaba el inicio del "diálogo" con los civiles, que sería conducido por el entonces ministro del Interior, el general Albano Harguindeguy. Se notificaba también "el análisis y promulgación de la legislación sobre el régimen de los partidos políticos y su normalización (...) a partir del segundo semestre de 1980", tal como se había establecido secretamente en el documento de trabajo del 5 de diciembre ${ }^{96}$.

\footnotetext{
${ }^{92}$ Acta $\mathrm{N}^{\mathrm{o}} 122 \ldots$, op. cit., p. 289 y ss.

${ }^{93}$ Op. cit., pp. 293-294.

${ }^{94}$ Bases políticas de las Fuerzas Armadas para el proceso de reorganización nacional, Acta $\mathrm{N}^{\circ} 124,19$ de diciembre de 1979, Actas de la dictadura, tomo 4, p. 20.

${ }^{95}$ Op. cit., p. 23.

${ }^{96}$ Véanse las Bases instrumentales..., op. cit., p. 286 y ss.
} 
Luego de casi cuatro años de gobierno el tan promocionado Plan Político de la dictadura argentina consistía tan solo en la enumeración de un puñado de principios y objetivos generales, y se agotaba en el solitario anuncio del "diálogo político". El mismo fue iniciado el 26 de marzo de 1980 por Albano Harguindeguy, que era acompañado por una "comisión política" (COMIPOL) con una compleja dinámica que incluía al Ministro, a la JM, a los secretarios generales de las Fuerzas Armadas, a un "equipo de compatibilización interfuerzas" permanente, a "un numero suficiente de auxiliares", y a un delegado militar por cada Fuerza Arma$\mathrm{da}^{97}$. La JM procuró mantener un estrecho control sobre la evolución del diálogo, aprobando sucesivas Orientaciones complementarias a las Bases políticas..., de acuerdo con los sucesivos "diagnósticos" sobre los avances de este primer acercamiento formal con los civiles ${ }^{98}$.

A los encuentros del diálogo concurrió un heterogéneo espectro de individuos: representantes de las principales corporaciones empresarias (la Sociedad Rural Argentina, el Consejo Empresario Argentino, la Cámara de Sociedades Anónimas, la Cámara de Comercio, la Asociación de Bancos Argentinos), e importantes empresarios que asistieron a "título personal"; algunas fracciones sindicales, la dirigencia de la Unión Cívica Radical, y algunos dirigentes del justicialismo, del desarrollismo, de la Fuerza Federalista Popular, del Partido Socialista Democrático, de la Democracia Progresista, de un sector de la Democracia Cristiana y de distintos partidos provinciales; miembros de colegios y academias profesionales; rectores de universidades estatales y privadas; directores de medios de comunicación, etcétera.

Las reuniones fueron regidas por un estricto protocolo: primero, se realizaba una reunión reservada entre los invitados y el ministro del Interior frente a un auditorio militar, y luego una rueda de prensa en la que los invitados se referían a dos de los puntos más delicados de las "premisas básicas": la legitimación de la "lucha contra la subversión" y la posición sobre el futuro papel de las Fuerzas Armadas ${ }^{99}$. Se realizaron encuentros tanto en el ámbito nacional como en el provincial y el municipal, donde las autoridades locales desempeñaron un papel fundamental, cumpliendo la misma función que Albano Harguindeguy cumplía a nivel nacional. Al entregar el informe final de su gestión, el ministro del Interior contabilizó la realización de "52 entrevistas en el orden nacional, con 215 personas, y 337 entrevistas en las provincias, con 1224 personas" ${ }^{100}$.

El excesivo despliegue de reaseguros con que las Fuerzas Armadas procuraron controlar este acercamiento con los civiles no pudieron evitar el fracaso de esta primera etapa del diálogo. Las "premisas básicas" tuvieron una incidencia fundamental en esta decisiva derrota del régimen militar: según Albano Harguindeguy, más allá de "significativas coincidencias" con los civiles convocados, estos habían presentado contundentes objeciones, por ejemplo, a la institucionalización de un "cuarto poder" militar ${ }^{101}$. La

\footnotetext{
${ }^{97}$ Acta $\mathrm{N}^{\mathrm{o}}$ 126, 26 de diciembre de 1979, anexo 1, Actas de la dictadura, tomo 4, p. 45.

${ }^{98}$ La Orientación complementaria $N^{\circ} 1$ de las Bases instrumentales para la acción política había sido aprobada por la JM poco antes del inicio del diálogo, en febrero de 1980; Acta No 128, 19 de febrero de 1980, Actas de la Dictadura, tomo 4, p. 49.

${ }^{99}$ Inés González Bombal, El diálogo politico, la transición que no fue, Buenos Aires, Estudios CEDES, 1991, p. 29.

${ }^{100}$ Diario La Nación, Buenos Aires, 26 de marzo de 1981.

${ }^{101}$ Ibid.
} 
acumulación de amenazas y temores había llevado al gobierno militar a replegarse sobre aquellos puntos mínimos de acuerdo interno sobre los que pretendía resguardar la integridad institucional de las Fuerzas Armadas.

En marzo de 1981 se inició una nueva etapa de la dictadura, con la asunción del general Roberto Viola, miembro de la fracción "politicista" del Ejército, como Presidente de la Nación. Desplegó una estrategia de acercamiento con las organizaciones políticas existentes, amplió sustantivamente la presencia civil en el gabinete nacional y en las gobernaciones ${ }^{102}$, y reclutó a individuos del personal subalterno de los partidos para ocupar las intendencias ${ }^{103}$. En junio, su ministro del Interior, el general Horacio Liendo, también miembro de la fracción "politicista", informó que el gobierno militar había confiado los "equipos ministeriales o intendencias" en un $90 \%$ a dirigentes civiles, "radicales, desarrollistas, intransigentes, justicialistas, federalistas, conservadores, democristianos, socialistas, de Nueva Fuerza, de Línea Popular (y de) casi todos los principales partidos provinciales"104.

Horacio Liendo emprendió un segundo capítulo del diálogo político, pero de características diferentes al de Albano Harguindeguy. Convocó a los dirigentes partidarios como tales (no a "título personal") y las reuniones fueron menos formales y se discutieron temas instrumentales de las Bases políticas..., en especial las reglamentaciones de la actividad partidaria ${ }^{105}$. Pero esta nueva modalidad provocó la inmediata resistencia de la JM, que aprobó las Orientaciones $N^{o} 2$ de las Bases instrumentales para la acción de gobierno ${ }^{106}$, solo una muestra de la feroz oposición interna que despertó el acercamiento del gobierno de Roberto Viola con la dirigencia política, y que provocó el derrocamiento del presidente en diciembre de $1981^{107}$.

Durante los primeros meses de 1982, la problemática del plan político estuvo ausente de las preocupaciones de la JM, atenta a los graves acontecimientos de la guerra de Malvinas contra Gran Bretaña y luego a la traumática posguerra, cuando el gobierno militar cayó en literal descomposición ${ }^{108}$. Recién tras la designación del "politicista" Reynaldo Bignone como último presidente del proceso, en el mes de julio, la dictadura anunció la sanción del Estatuto de los Partidos Políticos y "la firme e irrevocable decisión de las Fuerzas Armadas de institucionalizar constitucionalmente al país a más tardar en marzo de 1984" ${ }^{109}$.

Este retorno a las preocupaciones políticas respondía casi excluyentemente a la ausencia de alternativas de un régimen en descomposición, que ahora debía abocarse a preservar a las Fuerzas Armadas de la tangible disgregación, derivada de los crímenes

102 Paula Canelo, "Construyendo elites dirigentes. Los gobernadores provinciales durante la última dictadura militar (Argentina, 1976-1983)", en Anuario del Centro de Estudios Históricos "Prof. Carlos S. A. Segreti", año 11, No 11, Córdoba, 2011; Paula Canelo, "Los efectos del poder tripartito. La balcanización del gabinete nacional durante la última dictadura militar argentina", en Prohistoria, año. Xv, No 17 , Rosario, enero-junio 2012, pp. 129-150.

${ }^{103}$ González Bombal, Los vecinazos..., op. cit., p. 52.

${ }^{104}$ Diario Clarín, Buenos Aires, 10 de junio de 1981.

${ }^{105}$ González Bombal, op. cit., p. 84.

${ }^{106}$ Orientaciones $N^{\circ} 2$ de las Bases instrumentales para la acción de gobierno, Acta $N^{\circ} 176,14$ de abril de 1981, Actas de la dictadura, tomo 4, p. 188.

${ }^{107}$ Canelo, El proceso..., op. cit., p. 176.

${ }^{108}$ Op. cit., 192.

${ }^{109}$ Diario Clarín, Buenos Aires, 27 de agosto de 1982. 
del terrorismo, de la derrota en la guerra y del fracaso gubernamental. Sin embargo, la JM se negó a abandonar las "premisas básicas", que fueron incluidas en la Directiva de la Junta Militar al Poder Ejecutivo nacional para la concertación, que enumeraba "las acciones tendientes a concluir con la institucionalización del país"110. Allí era evidente que el gobierno militar abandonaba sus veleidades refundacionales para replegarse en la defensa de los intereses corporativos de las Fuerzas Armadas, especialmente el de lograr la impunidad por los crímenes cometidos, por entonces último recurso de cohesión institucional ${ }^{111}$. La premisa vinculada con "La convalidación de todo lo actuado en la lucha contra la subversión" y con impedir "cualquier revisionismo" se había impuesto sobre las demás; así, los "temas a concertar" con los civiles en el plano interno eran:

“1. Vigencia del estado de sitio (...); 2. Situación de los subversivos expatriados (...); 3. Mecánica y secuencia para el acto eleccionario y para la entrega del poder (Ley y Cronograma Electoral) (...); 4. Prescindencia política del gobierno (...); 5. Lucha contra el terrorismo. a. Vigencia y proyección de los logros obtenidos por la victoria militar sobre la subversión armada, en su carácter de triunfo logrado por toda la Nación (...). 6. Desaparecidos. Dado que la guerra contra la subversión ha dejado profundas heridas en la sociedad argentina, tanto en las familias de las victimas del terrorismo como en las de los que las provocaron (sic.), algunos de los cuales son desaparecidos, se proveerá a la opinión publica la información posible y se articulará con la dirigencia nacional los modos de acción necesarios para evitar la repetición de los dramáticos enfrentamientos que han socavado las bases de la sociedad argentina"112.

Anunciadas el 11 de noviembre de 1982 por cadena nacional de radio y televisión, las Pautas para la concertación económica, política y social fueron rechazadas por los máximos dirigentes políticos agrupados en la Multipartidaria ${ }^{113}$, "por ser extraña a la Constitución Nacional y condicionante del próximo gobierno elegido por el pueblo", mientras que se llamaba a una "movilización nacional de todos los sectores", pocos días después del paro nacional convocado por las principales asociaciones sindicales ${ }^{114}$.

La crisis era total. En el documento secreto Orientación para la acción de gobierno febrero 1983-enero 1984, la JM admitía "la pérdida de espacio político, de libertad de maniobra y de capacidad de convocatoria que ha sufrido el PRN"115. El texto dedicaba solo unas líneas a la "estrategia política", para concentrarse en preocupaciones vinculadas con la "lucha contra la subversión": ordenaba "Mantener a los medios operativos en condiciones de retomar la defensiva", y contrarrestar la "acción negativa" de los medios de comunicación social mediante "un empleo más eficaz y agresivo" de la "Acción Psicológica"116.

\footnotetext{
${ }^{110}$ Directiva de la Junta Militar al Poder Ejecutivo nacional para la concertación, Acta No 240, 10 de noviembre de 1982, Actas de la dictadura, tomo 5, p. 101 y ss.

${ }^{111}$ Canelo, El proceso..., op. cit., p. 194 y ss.

${ }^{112}$ Acta $\mathrm{N}^{\mathrm{o}}$ 240, 10 de noviembre de 1982, Actas de la dictadura, tomo 5, p. 106.

${ }^{113}$ En julio de 1981 se había constituido la Asamblea Multipartidaria, que nucleaba a dirigentes de la Unión Cívica Radical, el Partido Justicialista, el Movimiento de Integración y Desarrollo, el Partido Intransigente y el Partido Demócrata Cristiano.

${ }^{114}$ Diario Clarín, Buenos Aires, 17 de noviembre de 1982.

${ }^{115}$ Orientación para la acción de gobierno febrero 1983-enero 1984, Acta No 248, 14 de febrero de 1983, Actas de la dictadura, tomo 5, p. 163.

${ }^{116} \mathrm{Ibid}$.
} 
Finalmente, la JM recomendaba "Emitir el documento por el cual la Junta Militar presenta a la ciudadanía un cuadro desapasionado de los hechos ocurridos a lo largo de casi dos décadas, y por su intermedio a las Fuerzas Armadas, asumen la responsabilidad histórica frente a la Nación", y "sancionar los elementos legales adecuados"117.

Era el final. Conseguir la impunidad se había transformado en el objetivo excluyente, por ser el único que prometía mantener a las Fuerzas Armadas a salvo de la desintegración institucional. Hacia allí dirigió sus últimas energías el poder militar con la publicación, en abril de 1983, del Documento final de la Junta Militar sobre la guerra contra la subversión y el terrorismo, y de la llamada Acta institucional ${ }^{118}$, y en septiembre del mismo año, de la Ley de Enjuiciamiento de Actividades Terroristas y Subversivas o de Pacificación Nacional -N $N^{\circ} 22.924-$, conocida como "Ley de Autoamnistía" 119 . El paso decisivo hacia la descomposición del histórico poder militar argentino estaba dado.

\section{Conclusiones}

El Proceso de Reorganización Nacional mostró una ambición política formidable. Especialmente entre los años 1976 y 1979, el delicado problema de la definición del plan político de la dictadura mantuvo ocupadas las mentes y las plumas de muchos de sus funcionarios e ideólogos. Recurriendo, un tanto espasmódicamente, a la inspiración de autores variados como David Hume, Nicolás Maquiavelo, Juan Bautista Alberdi, Maurice Duverger, "Clausevitch" (sic.), José Ortega y Gasset, Gilbert Keith Chesterton, Winston Churchill, Montesquieu, el poeta Horacio o Crozier, encumbrados individuos y grupos muy activos en la interna política de la dictadura perfilaron el núcleo fundamental de la "cuestión política" del proceso. La misma amalgamó desafíos tan fundamentales como el de qué hacer con las organizaciones políticas y sindicales existentes, principal blanco de la experiencia refundacional; o el de cómo lograr la institucionalización del poder militar; o el de cómo gestar la descendencia política del proceso. Pero además, estos desafíos debían concretarse obteniendo el consenso de la sociedad argentina, por lo que el régimen se empeñó, permanentemente, en obtener su propia legitimación. Así lo entendieron sus exponentes más variados: el general Ramón Díaz Bessone cuando afirmaba que el consenso era uno de los "valores universales y permanentes sobre los cuales se ha constituido la Nación Argentina" ${ }^{20}$, y los "politicistas" de la Secretaría General cuando sostenían que "LEGITIMACIÓN significa CONSENSO"121.

En la práctica, gran parte de las energías desplegadas para concretar estos desafíos fue consumida por las tremendas dificultades que encontró el régimen para consensuar internamente su propuesta política, derivadas más de la profunda fragmentación políti-

\footnotetext{
${ }^{117}$ Orientación para la acción de gobierno febrero 1983..., op. cit., p. 163.

${ }^{118}$ Diario La Nación, Buenos Aires, 29 de abril de 1983.

${ }^{119}$ Op. cit., 24 de septiembre de 1983.

${ }^{120}$ Proyecto nacional..., op. cit., p. 260.

${ }^{121}$ Plan de acción política..., op. cit., p. 25 y ss., mayúsculas en el original, aquí versales.
} 
co-ideológica de su frente interno que de la acción de alguna oposición externa. Entre sus filas coexistían desde posiciones más "duras" y corporativistas, herederas del Onganiato, que planificaban acercamientos con los civiles en plazos no menores a los doce años mientras el terrorismo de Estado destruía de raíz las desviaciones de una sociedad "desquiciada", hasta versiones más "políticistas", que preferían acordar en el corto plazo con las dirigencias políticas existentes antes que perder la oportunidad refundacional. Los conflictos también enfrentaban, por ejemplo, a quienes observaban las experiencias de las dictaduras vecinas y proponían reformar la Carta Magna, con quienes entendían que era suficiente un referendum que viabilizara una pronta institucionalización del país, o a quienes postergaban la definición de plazos a la realización de objetivos, con quienes advertían sobre la conveniencia de delimitar instrumentos y plazos concretos de acción.

En la feroz lucha desatada en torno a la definición de los objetivos políticos del régimen, los primeros lograron bloquear los avances de los segundos. En efecto, la desactivación de las propuestas más pragmáticas del proceso fue evidente luego de los procesos de "compatibilización" intra e interfuerzas que se desarrollaron desde 1977, concluidos los cuales fue la mismísima JM la que tomó en sus manos la cuestión del Plan Político, pero para producir las tardías e inconducentes Bases políticas de diciembre de 1979.

Pero sobre todas las propuestas de las diferentes fracciones internas que albergó el gobierno dictatorial, triunfaron, sin duda, el agotamiento de los tiempos políticos y el peso de los atroces crímenes cometidos por las Fuerzas Armadas en el marco de la represión. El extendido involucramiento de los militares argentinos en la ejecución del terrorismo de Estado y el énfasis puesto por la dictadura argentina en la legitimación "antisubversiva" fue un arma de doble filo: logró consolidarse como el principal recurso de cohesión del poder militar en desintegración, pero bloqueó las oportunidades de avanzar en la refundación política. En forma progresiva, y muy especialmente a partir de la visita de la Comisión Interamericana de Derechos Humanos de la OEA en 1979, la "cuestión política" fue perdiendo espacio dentro de la agenda del máximo órgano militar, espacio que fue ocupado por el puñado de "premisas básicas no negociables" que inspiraban acuerdo dentro del convulsionado frente militar. Y también, tal como lo habían advertido desde temprano algunos documentos reservados, una de ellas se impuso nítidamente por sobre todas las demás: la amnistía.

Este trabajo muestra que el nivel municipal fue un eslabón fundamental del plan político general de la dictadura argentina, y que su jerarquización fue un propósito de largo alcance del régimen, por varias razones.

Primero porque el municipio, considerado "célula básica de la organización política" 122 argentina, fue el instrumento político que acompañó el intrincado entramado "capilar" de control territorial y poblacional característico de la dictadura. En la encrucijada entre la necesidad y búsqueda de consenso, y la oclusión de los canales tradicionales de expresión de intereses, los municipios argentinos fueron la "periferia del poder" hasta la que se esmeró por llegar el poder militar. De allí la cuidadosa delimitación de funciones políticas entre gobernadores e intendentes, y también sus contrastantes reclutamientos.

\footnotetext{
${ }^{122}$ Declaraciones del ministro Albano Harguindeguy en diario La Nación, Buenos Aires, 26 de marzo de 1981.
} 
Segundo, el municipio fue el espacio que la dictadura argentina reservó para el ejercicio de una "ciudadanía municipal", apolítica y local, basada en la "convivencia solidaria" entre vecinos, y orientada a la resolución de problemas cotidianos. La misma debía estar organizada en asociaciones pequeñas, vecinales, de fomento, y otras "entidades intermedias" que debían reemplazar a los conflictivos y masivos partidos políticos y organizaciones sindicales. Esta "ciudadanía municipal" se correspondía tanto con las concepciones corporativistas de la participación del Proyecto nacional, como con el elitismo del general Ibérico Saint Jean y del civil Jaime Perriaux, que reservaban el ejercicio de la "política con mayúsculas" en el nivel nacional-programático ${ }^{123}$ para un grupo reducido y encumbrado de notables, militares y civiles.

Tercero, el nivel municipal fue postulado como un "laboratorio" adecuado para avanzar en la apertura política, una etapa fundamental en los planes de instrumentación del futuro proceso electoral. La realización de elecciones "piloto" en el nivel municipal como primer paso de un proceso de elecciones escalonadas hasta llegar al nivel nacional, prometía mantener el proceso bajo control del gobierno militar, mientras se abría lentamente la "caja negra" de la opinión pública argentina.

Cuarto, el municipio fue considerado el ámbito legítimo de gestación de la "dirigencia natural" argentina: fue el soñado semillero del MON. El nivel local fue el locus autorizado tanto para la participación comunitaria de la "ciudadanía municipal" como para el surgimiento de la "auténtica dirigencia", condición de la refundación de las elites argentinas que se proponía la dictadura. Privados del ejercicio de la "alta política", los "ciudadanos municipales" legitimarían a estos "notables locales" por el conocimiento personal, la cercanía y la confianza, de acuerdo con su desempeño en la resolución de problemas puntuales y cotidianos.

La referencia a la experiencia dictatorial chilena y su proceso de "alcaldización de la política" 124 es clave para comprender la importancia alcanzada por el nivel municipal dentro del plan político general de la dictadura argentina. La evidencia disponible, aunque disímil para ambos casos, permite identificar elementos comunes y diferencias entre ambas experiencias autoritarias.

Por un lado, ambas dictaduras jerarquizaron al municipio como "centro materializador" de la resocialización política de la sociedad. Como han mostrado investigaciones recientes ${ }^{125}$, la dictadura de Augusto Pinochet también buscó emplear la "municipalización política" de la sociedad para exorcizar los peligros de la participación social en poderosas y conflictivas organizaciones, como los partidos políticos y las asociaciones sindicales. Tanto el régimen chileno como el argentino postularon una "democracia de verdadera participación social", que en ambos casos fue orientada por concepciones corporativistas: protagonizada por las "entidades intermedias", muy controlada por el Estado y orientada a la resolución de los problemas comunitarios cotidianos ${ }^{126}$. Además,

${ }^{123}$ Declaraciones del ministro Albano Harguindeguy en diario La Nación, Buenos Aires, 3 de mayo de 1978.

${ }^{124}$ Valdivia Ortiz de Zárate, Álvarez y Donoso, op. cit., p. 7 y ss.

${ }^{125}$ Valdivia Ortiz de Zárate, “¡Estamos en guerra...”, op. cit., 163 y ss.; Verónica Valdivia Ortiz de Zárate, "Al rescate del municipio. La síntesis ideológica de la dictadura pinochetista", en Observatorio Latinoamericano, $\mathrm{N}^{\circ}$ 8, Buenos Aires, agosto 2011, pp. 108-133.

${ }^{126}$ Sobre la influencia de la ideología corporativista en la dictadura chilena, Gabriela Gomes, "Las tradi- 
varios estudios han mostrado la importancia estratégica que tuvieron, en el caso argentino, algunos intendentes como agentes de implementación del proyecto autoritario y de construcción de apoyos políticos al régimen en el plano local ${ }^{127}$, tal como sucedió en la experiencia de "alcaldización" chilena.

Sin embargo, en el caso argentino el municipio no llegó a articular una "síntesis ideológica" en los elencos de gobierno, como sí parece haber sucedido en el caso chileno, donde el fervor por lo municipal logró reunir "las propuestas de orden castrense, neoliberal y gremialista" ${ }^{128}$. En Argentina esta síntesis parece haber sido impedida, por ejemplo, por la presencia de los "politicistas" en las altas esferas del gobierno, que no le atribuyeron al nivel municipal la misma jerarquía que le otorgaron otras fracciones internas. Los municipios argentinos no llegaron a consolidarse y proyectarse hacia el futuro como "entes estatales clave de la vida ciudadana", ni la alcaldización se transformó en "el nuevo estilo de hacer política", como sí parece haber sucedido en el caso chileno $^{129}$.

En suma, la "municipalización política" en Argentina no presentó la profundidad ni el éxito de la experiencia chilena. Diferencias ideológicas y políticas entre ambas alianzas gubernamentales, la disímil extensión y profundidad de las respectivas políticas represivas, las configuraciones gubernamentales y las dinámicas políticas específicas de cada caso, entre otros elementos, probablemente puedan explicar por qué la dictadura argentina no logró, a diferencia de la chilena, consolidar su propia experiencia de municipalización; uno más de la larga serie de extravíos políticos que la caracterizaron.

ciones corporativistas en la dictadura pinochetista", en Observatorio Latinoamericano, $\mathrm{N}^{\mathrm{o}}$ 8, Buenos Aires, agosto 2011, pp. 134-149.

${ }^{127}$ Entre otros, González Bombal, Los vecinazos..., op. cit., p. 49 y ss.; Rodríguez, "Descentralización...”, op. cit., p. 369 y ss.

${ }^{128}$ Valdivia Ortiz de Zárate Ortiz de Zárate, La alcaldización..., op. cit., p. 13.

${ }^{129}$ Valdivia Ortiz de Zárate, Álvarez y Donoso, op. cit., p. 8. 